\title{
Heterosynaptic Facilitation of Tail Sensory Neuron Synaptic Transmission during Habituation in Tail-Induced Tail and Siphon Withdrawal Reflexes of Aplysia
}

\author{
Mark Stopfer ${ }^{1}$ and Thomas J. Carew ${ }^{1,2}$ \\ Departments of ${ }^{1}$ Psychology and ${ }^{2 B}$ Biology, Yale University, New Haven, Connecticut 06520-8205
}

In cellular studies of habituation, such as in the gill and siphon withdrawal reflex to tactile stimulation of the siphon of Aplysia, a mechanism that has emerged as an explanation for response decrement during habituation is homosynaptic depression at sensory neurons mediating the behavioral response. We have examined the contribution of homosynaptic depression to habituation in sensory neurons that contribute to two reflex behaviors in Aplysia, tail withdrawal and siphon withdrawal, both elicited by threshold-level tail stimulation. In a companion paper (this issue), we reported that repeated tail stimulation, identical to that producing habituation in siphon withdrawal in freely moving animals, also produces habituation in reduced preparations. In this paper, we extend these behavioral findings by showing that in reduced preparations, identical tail stimulation also produces habituation of the tail withdrawal reflex. In addition, our cellular experiments show that (1) identified sensory and motor neurons in both reflex systems respond to identical repeated tail stimulation; in sensory neurons it produces a progressive decrease in spike number and increase in spike latency, and in motor neurons it produces progressive decrement in complex EPSPs and spike output. (2) Homosynaptic depression of the tail sensory neuron to tail motor neuron synapse does occur when the sensory neurons are activated repetitively by intracellular current. (3) Homosynaptic depression at this synapse does not occur when the sensory neurons are activated repetitively by threshold-level tail stimuli that elicit the behavioral reflex and cause habituation; rather, the sensory neurons exhibit significant heterosynaptic facilitation. Thus, in these reflexes, habituation is not accompanied by homosynaptic depression at the sensory neurons, suggesting that the plasticity underlying habituation occurs primarily at interneuronal sites.

Key words: Aplysia; habituation; homosynaptic depression; heterosynaptic facilitation; learning; memory
Understanding the cellular mechanisms that underlie learning and memory is a major objective in neuroscience. In recent years considerable progress toward this goal has been made by examining relatively simple preparations in which learned behavioral modifications can be related to training-specific modifications at the cellular level (for reviews, see Carew and Sahley, 1986; Byrne, 1987).

Among the different forms of learning, perhaps the simplest and most widely observed is habituation, the progressive decrement in response strength occurring when a response is elicited repeatedly. The neural basis of habituation has been studied in several preparations. In those preparations in which a cellular analysis has been possible, one mechanism that has emerged as an attractive explanation for the response decrement accompanying habituation is homosynaptic depression (a progressive decrease of excitatory synaptic transmission) from primary sensory neurons that mediate the behavior (Krasne, 1969; Castellucci et al., 1970; Zucker, 1972). This decrease in excitatory input to the circuit

Received Feb. 5, 1996; revised May 22, 1996; accepted May 24, 1996.

This work was supported by National Science Foundation Grant BNS831130, National Institutes of Health Grant R01-MH-14-1083, and Air Force Office of Scientific Research Award AF 89-0362 to T.J.C. We gratefully acknowledge Drs. Truett Allison, Michael Davis, Nelson Donegan, Gail M. Gottfried, and Allan Wagner for useful discussions at various stages of this work, and Drs. John Byrne, Thomas Fischer, Kent Fitzgerald, Eric R. Kandel, and Edgar T. Walters for helpful comments on this manuscript.

Correspondence should be addressed to Thomas J. Carew, Yale University, Department of Psychology, P.O. Box 208205, New Haven, CT 06520-8205.

Dr. Stopfer's present address: California Institute of Technology, Division of Biology 139-74, 1201 East California Boulevard, Pasadena, CA 91125.

Copyright (C) 1996 Society for Neuroscience $0270-6474 / 96 / 164933-16 \$ 05.00 / 0$ mediating the response is thought to translate into a progressive decrease in motor neuronal output and thus a diminished behavioral response (Kupfermann et al., 1970; Hawkins et al., 1993). One preparation in which this general hypothesis has been articulated in some detail is the marine mollusc Aplysia, where homosynaptic depression of sensory neurons has been implicated in habituation in the gill and siphon withdrawal reflex to tactile stimulation (Castellucci et al., 1970).

Homosynaptic depression is a well studied form of synaptic plasticity in primary sensory neurons of Aplysia. Many studies have shown that repeated, direct intracellular activation of these cells reliably causes progressive depression of excitatory synaptic transmission (Castellucci et al., 1970; Klein et al., 1980; Byrne, 1982; Walters et al., 1983; Hawkins et al., 1987; Buonomano et al., 1992; Goldsmith and Byrne, 1993). Moreover, several studies in Aplysia have demonstrated habituation in behaving animals and in reduced preparations (Kupfermann et al., 1970; Pinsker et al., 1970; Carew et al., 1972; Stopfer and Carew, 1987); however, the role of sensory neuron homosynaptic depression in producing habituation in Aplysia so far has been examined only in the siphon-elicited gill and siphon withdrawal reflex (Castellucci et al., 1970; Carew et al., 1971; Castellucci et al., 1978; Hawkins and Frost, 1995).

The purpose of our experiments was to examine the contribution to habituation of homosynaptic depression in sensory neurons involved in two different response systems, both triggered by a common population of tail sensory neurons in Aplysia: tailelicited tail withdrawal and tail-elicited siphon withdrawal. These two response systems represent two broad classes of reflex cir- 
cuitry. (1) Tail-elicited tail withdrawal has both direct (monosynaptic) and indirect (polysynaptic) sensory neuron input onto tail motor neurons (in this respect it is like siphon-elicited gill and siphon withdrawal); (2) tail-elicited siphon withdrawal has only indirect input onto siphon motor neurons. This latter reflex has been used previously by Walters $(1987 \mathrm{a}, \mathrm{b})$ to examine behavioral and cellular modifications accompanying site-specific sensitization, and by Scholz and Byrne (1987) to examine alterations of tail sensory neurons during long-term sensitization in Aplysia.

We have recently shown that the tail-elicited siphon withdrawal reflex exhibits both short-term and long-term habituation in freely moving, intact animals and in reduced preparations [Stopfer and Carew, 1994; Stopfer et al., 1996 (companion paper)]. In the present studies, we have confirmed and extended these findings by showing that (1) in addition to the siphon withdrawal reflex, the tail-elicited tail withdrawal reflex also exhibits habituation when stimulation parameters identical to those used in freely moving animals are applied to reduced preparations; (2) identified sensory and motor neurons in both reflex circuits respond to the identical tail stimuli that are just at the threshold for triggering the reflexes in freely moving animals; (3) in response to repeated tail stimulation, complex synaptic input to the motor neurons for both reflexes, as well as their motor output, exhibits decrement that closely parallels behavioral habituation; (4) homosynaptic depression does occur in the tail sensory neurons when they are repetitively activated by intracellular current injection, but (5) homosynaptic depression does not occur when the sensory neurons are repetitively activated by the same (threshold-level) tail stimuli that can generate the behavioral reflex and cause habituation. Rather, the sensory neurons exhibit marked heterosynaptic facilitation during habituation. Thus, habituation in these two reflexes is not accompanied by homosynaptic depression at the primary sensory neurons, suggesting that the primary change producing habituation in these reflexes is likely to occur at interneuronal sites.

Preliminary results of some of the data described in this paper have been reported previously in abstract form (Stopfer and Carew, 1994).

\section{MATERIALS AND METHODS}

\section{Animals}

Reduced behavioral preparations. The reduced preparation has been described in detail in the companion paper (Stopfer et al., 1996). Briefly, animals were anesthetized by cooling to $3^{\circ} \mathrm{C}$ and were implanted bilaterally in the tail with fine silver wire electrodes identical to those used in freely moving animals (Stopfer et al., 1996). The digestive organs of the animals and most of the body anterior to the mantle were removed. Peripheral nerves other than P9 (which innervates the tail) and the siphon nerve were transsected. A catheter was inserted into the medial, posterior portion of the foot and secured in place with 6-0 ethilon (Ethicon) surgical thread, and for siphon withdrawal experiments, a second catheter was inserted into the aorta. Siphon withdrawal was elicited by weak (threshold level) tail stimuli (AC shock, $60 \mathrm{~Hz}, 100 \mathrm{msec}$ in duration, determined individually for each preparation). This level of stimulation produced a withdrawal reflex comparable in form and duration to a light tactile stimulus to the siphon skin. The response was quantified by an observer who timed responses from the start of withdrawal until the first indication that the siphon was beginning to relax. One side of the tail was chosen randomly to receive habituation training; the other side served as a control. Experiments were conducted "blind" such that during training, the observer did not know which side of the preparation received control or training stimuli.

For tail withdrawal experiments, a fine lacquered steel antenna wire was attached to the tip of the tail. This light-weight antenna had no apparent influence on siphon or tail behavior. Tail withdrawal was then detected and quantified by an automated movement transducer that tracked the position of the antenna wire and generated a voltage output proportional to tail displacement (Stopfer et al., 1996). Preparations were maintained at $15-18^{\circ} \mathrm{C}$ and perfused with a cooled, aerated Ringer's solution. Experiments were begun 1 to $2 \mathrm{hr}$ after the dissection.

Cellular preparations. Animals were anesthetized by injection with isotonic magnesium chloride and placed dorsal-side up in a wax-bottom dissecting tray. The parapodia were trimmed away to reveal the siphon, and the ink gland was removed to make pinning easier in a later stage of the procedure.

The animal was then placed ventral-side up and dissected as described previously (see above; also see Stopfer et al., 1996). In addition, the tail and siphon were separated surgically to prevent locomotory tail movements from confounding automatically measured siphon movements; the tail was cut free just posterior to the mantle cavity, with care taken to avoid damaging branches of the P9 nerves. Ganglia were partially fixed for $45-60 \mathrm{sec}$ in a $0.5 \%$ glutaraldehyde solution to reduce ganglionic movement during training.

Then the preparation was transferred to a two-part recording chamber with a Sylgard-coated floor filled with cool Ringer's solution. One part of the chamber was sufficiently deep $(6 \mathrm{~cm})$ to contain a completely submerged tail and siphon. The other part was a shallow, elevated stage with a transparent base for transilluminated viewing of the ganglia. The whole chamber was surrounded by an ice bath, which maintained the preparation at $\sim 15-18^{\circ} \mathrm{C}$. Fresh, aerated Ringer's solution was perfused into the aorta and tail through catheters. A constant bath level was maintained by an adjustable suction tube.

The tail and mantle areas were pinned in place. The tail was pinned loosely so that it would assume a fairly natural posture and degree of movement once reinflated by perfusion. Loose pinning also substantially reduced tugging against the pins caused by spontaneous and evoked tail movements. The preparation is illustrated in Figure 1.

The pleural and pedal, or in some cases the abdominal ganglia, were pinned tightly in place with Minutien pins. Care was taken to avoid stretching the nerves beyond the normal lengths found in the intact animal. The ganglia were then desheathed with iridectomy scissors to reveal the neurons within. A very fine steel antenna wire was attached to the siphon. Because the siphon undergoes less spontaneous movement than the tail, and because tail and siphon withdrawal reflexes exhibit similar habituation profiles (see Fig. 2), only siphon withdrawal was monitored during cellular experiments.

For one experiment, the mantle organs including the siphon were removed, and extracellular recordings were made from the cut end of the siphon nerve. The freshly cut nerve was aspirated into a tight-fitting, fire-polished glass microelectrode filled with Ringer's solution and containing an $\mathrm{Ag} / \mathrm{AgCl}$ electrode. Action potentials from the siphon nerve were amplified differentially by an extracellular amplifier (Grass P511A). Extracellular action potentials were detected by a window discriminator (Haer) and counted by a computer-driven device for a period of $5 \mathrm{sec}$ after each stimulus, a period of time roughly equal to the duration of nonhabituated siphon withdrawal responses.

\section{Intracellular recording}

During intracellular recording experiments, tail stimuli were delivered by the same AC shock-generating apparatus used in all of the intact animal and reduced preparation experiments described previously (see above, and Stopfer et al., 1996). Siphon withdrawal amplitude was measured by a computerized movement transducer.

Standard intracellular recording techniques were used. Glass microelectrodes (resistance 5-15 M $\Omega$ ) were filled with potassium acetate or potassium chloride. Recordings were made through $\mathrm{Ag} / \mathrm{AgCl}$ wire connected to intracellular amplifiers (Getting $5 \mathrm{~A}$ ) and displayed on a storage oscilloscope (Tektronix 5111A). Records of cellular activity were made by a chart recorder (Gould RS 3600), a magnetic tape data recorder (Vetter D1), and a computerized data acquisition system (Spike software, Hilal Associates). The acquisition system provided measurements of EPSP height, duration, and integrated area.

\section{Experimental procedures}

$\mathrm{LFS}_{\mathrm{B}}$ siphon motor neurons were identified by their characteristic position on the ventral surface of the abdominal ganglion, by their ability to generate a specific tailward movement of the siphon when depolarized by intracellular current injection, and by their vigorous firing in response to tactile tail stimulation delivered to either side of the tail (Frost et al., 1988; Hickie and Walters, 1995). Tail motor neurons were identified on the basis of their location in the pedal ganglia, their size, and their 


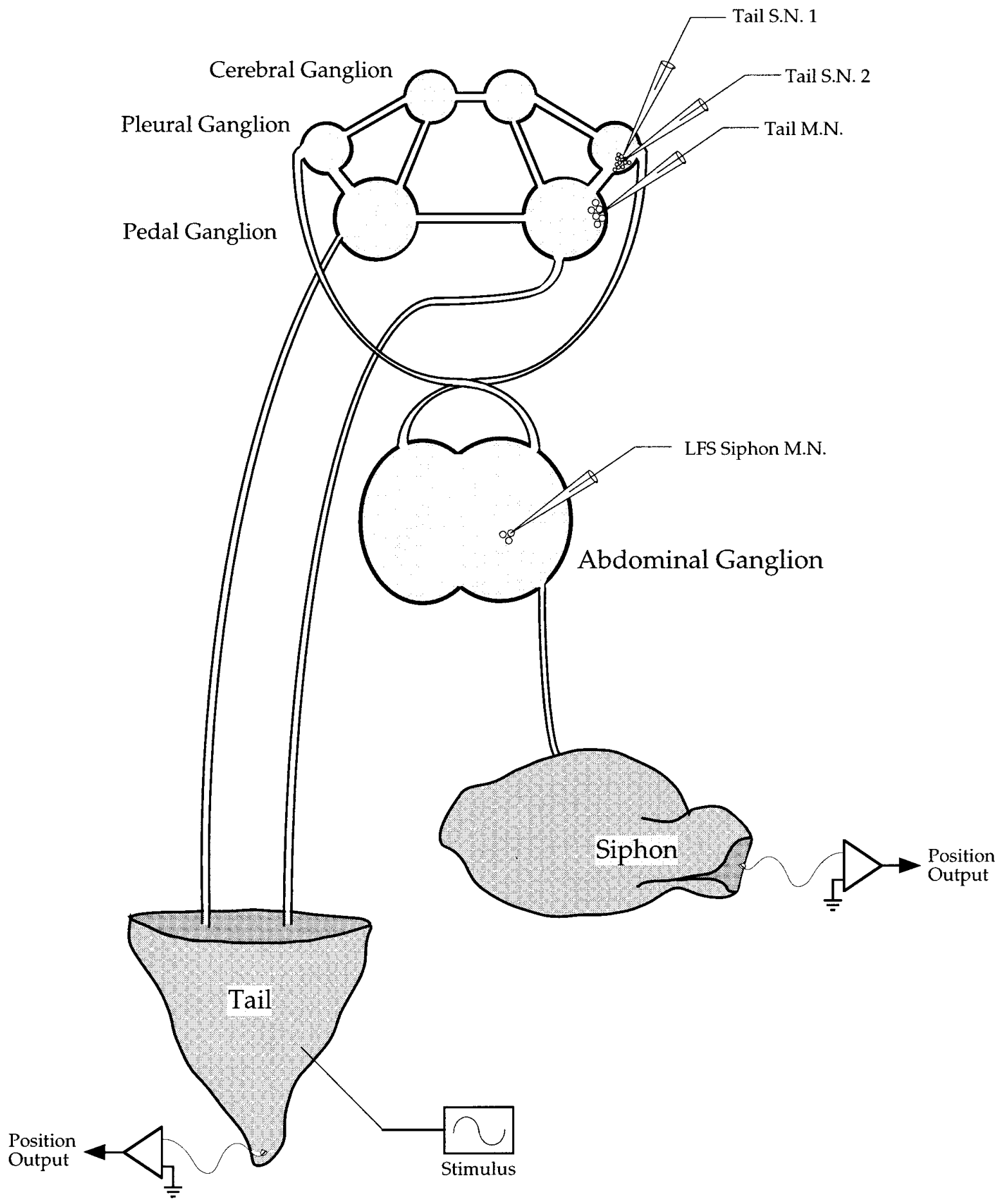

Figure 1. Schematic diagram of experimental preparation. Electrical stimuli identical to those used for freely moving and reduced preparations were delivered to the tail while siphon withdrawal (Stopfer et al., 1996) or tail withdrawal was monitored simultaneously by an automated movement transducer. Intracellular responses to the stimuli were recorded in identified tail sensory and tail motor neurons and identified siphon motor neurons. (See Materials and Methods for details.)

characteristic firing patterns, both spontaneous and in response to tail stimuli (Walters et al., 1983). The motor neurons were usually hyperpolarized $\sim 10 \mathrm{mV}$ by current injection, just enough to suppress spontaneous action potentials.

Tail sensory neurons throughout the ventral cluster (Walters et al., 1983) were identified on the basis of their position in the pleural ganglia, their size, their absence of spontaneous activity, and their responsiveness to gentle, punctate pressure from a fire-polished glass probe on the tail (Walters et al., 1983). Once such a sensory neuron was identified, an electrode was implanted into the tail in the receptive field that had been located by use of the probe. The stimulation electrodes had uninsulated, coiled tips that were inserted into the thin muscle layer, and thus remained firmly in place throughout the duration of the experiment. The threshold tail stimulus intensity was determined by gradually increasing the current from zero until a small siphon withdrawal was observed. This amount of electric current also elicited a barrage of action potentials in the sensory neuron that was comparable to that produced by a brief mechanical stimulus applied to the tail. 
A Siphon Withdrawal

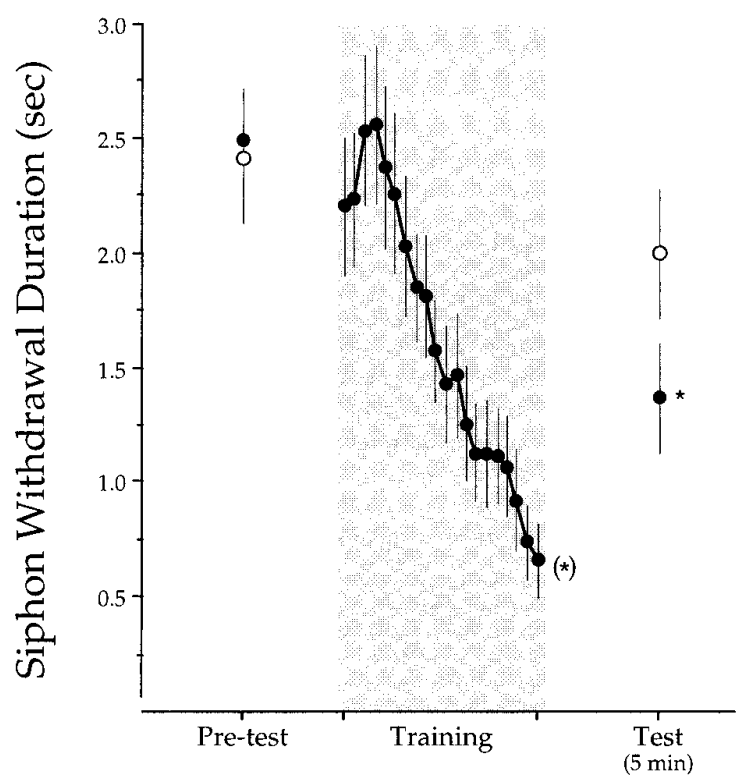

B Tail Withdrawal

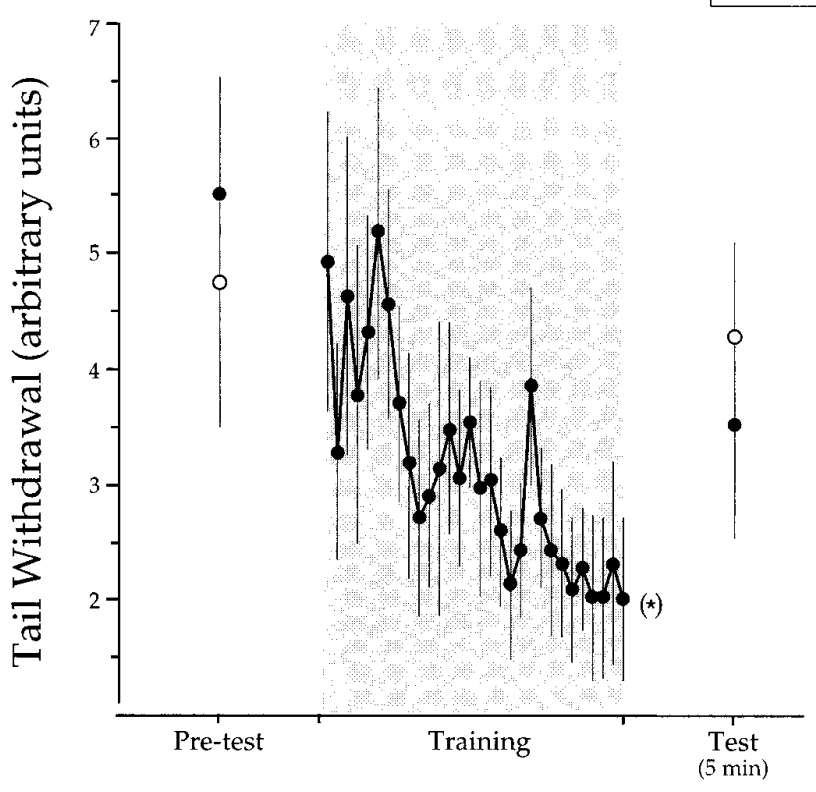

Figure 2. Both siphon withdrawal and tail withdrawal reflexes exhibit side-specific habituation. Only stimuli repeatedly delivered to trained sides of the tail (closed circles) produce habituation in a reduced preparation. Control sides (open circles) show no significant change. Responses during training are indicated by shading. $A$ is replotted from data reported in the companion paper in this issue (Stopfer et al., 1996). Measurements in $B$ were made by an automated movement transducer; arbitrary units reflect a voltage output proportional to tail displacement. Statistical significance ( $p \leq 0.05$; see text) is indicated in this and subsequent figures by the following symbols: *, within-group significance (data point is significantly different from its own pretest); $(*)$, aggregate significance (the series of data points to the left of the symbol are significantly different overall from one another, as determined by ANOVA); **, between-group significance (data points above and below symbol are significantly different from each other).

After dissection or implantation of an electrode, preparations were always allowed to rest for $60-90$ min before experiments began so that any short-term effects of these procedures could wear off. For example, this was sufficient time for EPSPs in the follower motor neurons (elicited by spikes in the sensory neurons) to return to preimplantation amplitudes and then remain stable for at least $30 \mathrm{~min}$.

\section{Synaptic analysis}

For experiments in which synaptic potentials were analyzed, two sensory neurons were identified, both making monosynaptic connections to the same tail motor neuron (Walters et al., 1983). These procedures were analogous to experiments performed on intact animals, as described in the companion paper (Stopfer et al., 1996). Both of the sensory neurons received a series of baseline tests delivered at an alternating, nondecrementing, 5 min ISI. Baseline testing consisted of eliciting a single action potential from the sensory neuron and recording the resulting monosynaptic EPSP at the motor neuron. These stimuli were delivered until a stable baseline had been obtained. [Stability was defined as three comparable, consecutive responses from both neurons, representing $30 \mathrm{~min}$ without substantial $(<10 \%)$ response change.] These final three baseline tests were designated "pretests" and were collapsed into single average pretest scores. After the pretests, one of the following two procedures was conducted.

For an analysis of homosynaptic depression, one of the two sensory neurons was chosen randomly to receive "training" (ISI = $30 \mathrm{sec}$ ) consisting of intracellular current injected in a pattern that closely mimicked the tail-shock-induced barrage of action potentials. In these experiments, the "trained" sensory neuron responded with a spike barrage just as it had during training by tail stimuli; however, in this case, no other sensory neurons were activated simultaneously, as would most likely occur during actual tail stimulation.

For an analysis of synaptic decrement during habituation, sensory neurons were activated by threshold tail-training stimuli that caused behavioral decrement. First, a tail motor neuron and two sensory neurons, both making monosynaptic connections to that motor neuron, were identified. Next, the tail receptive field for one of the sensory neurons was located using a fire-polished glass probe. An electrode was then implanted into the center of the receptive field. Thus, one (but not the other) sensory neuron could be activated by tail stimuli. A threshold-level tail stimulus intensity was selected to evoke a small but reliable siphon withdrawal. The tail motor neuron was hyperpolarized $15-20 \mathrm{mV}$ by intracellular current injection to prevent spiking in response to the tail stimulus. After the usual resting period, a series of 30 tail-training stimuli (ISI $=30 \mathrm{sec}$ ) evoked siphon withdrawal responses and tail motor neuron complex EPSPs, both of which were monitored. It was not possible to discern the unique contribution of the sensory neuron-evoked monosynaptic EPSP to the complex EPSP evoked by tail stimulation; therefore, single spikes were induced by intracellular current injection in the sensory neurons 15 sec after each tail stimulus, and the resulting monosynaptic EPSPs in the motor neuron were recorded.

Five minutes after the conclusion of either intracellular or tail stimulus training protocols, both sensory neurons received a test: as in pretesting, single action potentials were elicited from the sensory neurons, and the resulting EPSPs in the motor neuron were recorded.

\section{Statistical analysis}

The statistical significance of trends, such as those occurring during the course of a training procedure, was determined by ANOVA. Planned, single-level comparisons were made with $t$ tests. Multiple or post-hoc comparisons were made with Newman-Keuls tests. All results are expressed as means $\pm \mathrm{SEM}$, and all probability values are two-tailed.

\section{RESULTS}

\section{Both siphon and tail withdrawal reflexes exhibit habituation in the reduced preparation}

In reduced preparations, both the siphon withdrawal and the tail withdrawal reflexes exhibited significant habituation in response to repeated presentations of the same stimuli (brief, thresholdlevel electrical pulses to the tail) that induce habituation in freely moving animals (Stopfer and Carew, 1994). In the example shown in Figure $2 A$ (replotted from results described in Stopfer et al., 

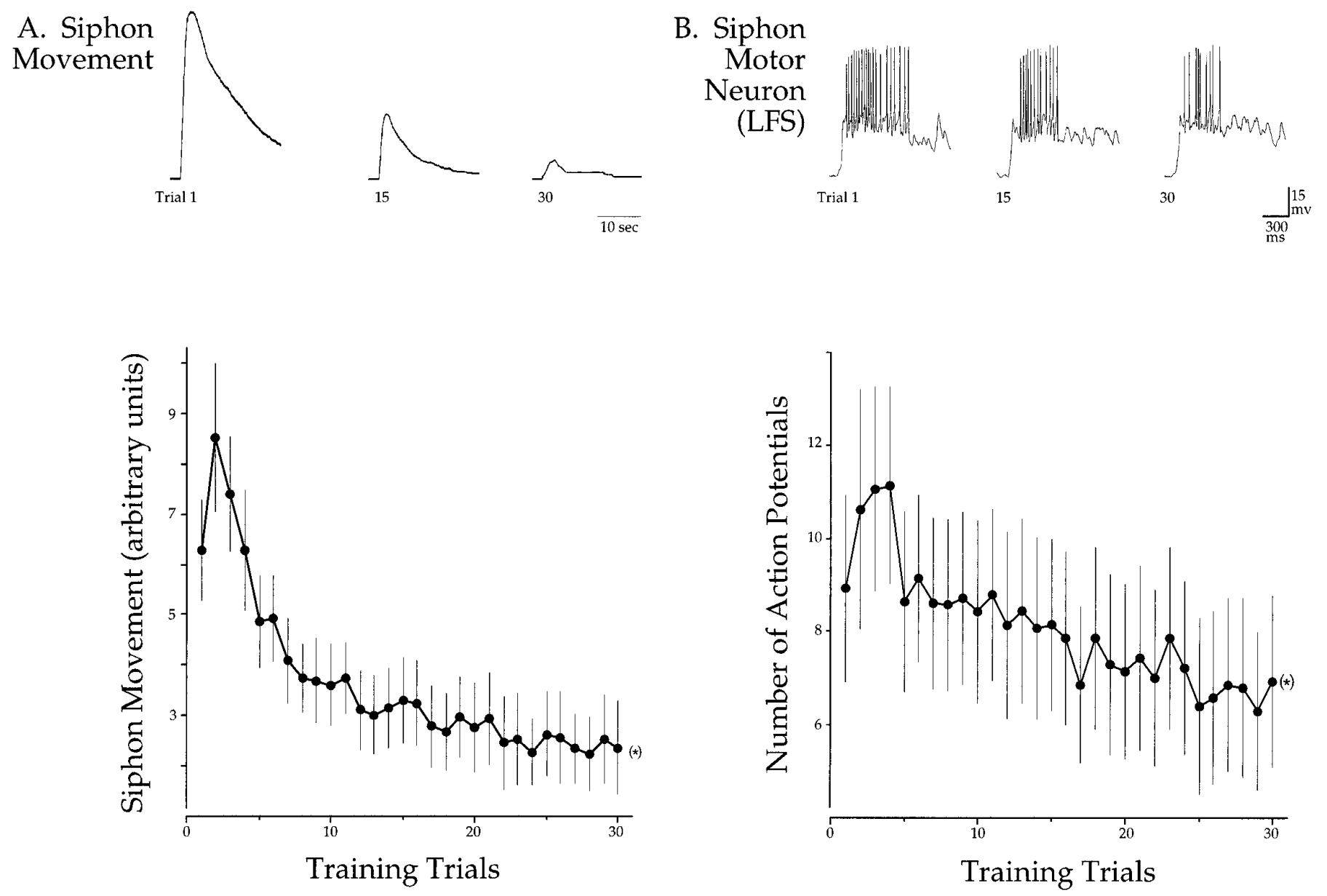

Figure 3. Training causes habituation of siphon withdrawal and simultaneous decrement of action potential number in a siphon motor neuron. $A$, Siphon withdrawal habituation. Top, Examples of siphon responses to training trials (ISI $=30 \mathrm{sec}$ ), recorded by the movement transducer. Bottom, Group summary for siphon response amplitude over trials. $B$, Siphon motor neuron response decrement. Top, Examples of siphon motor neuron responses (training trials are indicated). Bottom, Group summary shows a significant reduction in the number of action potentials per response over trials. See legend to Figure 2 for statistical significance indicated by asterisks.

1996) in 13 preparations in which siphon withdrawal was measured, the siphon reflex showed significant decrement during training.

Tail withdrawal similarly exhibited significant habituation, as shown in Figure $2 B$. In six preparations, using the same stimulation procedure used for siphon withdrawal, the tail reflex significantly habituated during training (ANOVA: $F_{(29,145)}=2.34, p<$ $0.001)$. Both sides of the tail were tested 5 min after training ended. The control sides were virtually unchanged compared with their own prescores (mean dif $=0.47 \pm 1.65, t_{(5)}=0.28$, NS). As is often the case with weak eliciting stimuli, habituation produced with these few stimuli was transient (Thompson and Spencer, 1966). Thus, on the trained side some recovery had occurred; responses elicited there still tended to be smaller than those elicited on the control side, but they were no longer significantly different from their own pretest levels (mean dif $=-2.00 \pm 1.42$, $\left.t_{(5)}=1.41, \mathrm{NS}\right)$.

Taken collectively, these results indicate that the same stimuli that cause habituation in freely moving animals (Stopfer and Carew, 1994; Stopfer et al., 1996) also cause habituation in reduced preparations that are amenable to a cellular analysis.

The overall effort to locate and analyze potential sites of plasticity contributing to habituation required a systematic examina- tion of neurons known to participate in tail and siphon withdrawal reflexes. Specifically, it was important to determine whether identified sensory and motor components of the tail-elicited withdrawal reflexes actually participated in the response generated by the weak, threshold-level tail stimuli used in the behavioral studies described above. Also, to pinpoint potential sites of plasticity, it was essential to characterize the responses of these neurons during the course of actual behavioral habituation training. Therefore, a series of recordings was made from each of the known sensory and motor components of the reflex.

\section{Siphon and tail motor neurons respond to behavioral training stimuli}

$\mathrm{LFS}_{\mathrm{B}}$ siphon motor neurons have previously been shown to contribute to the siphon withdrawal reflex (Frost et al., 1988). To determine whether these cells do in fact respond to the stimulus used in our behavioral experiments, both siphon withdrawal and $\mathrm{LFS}_{\mathrm{B}}$ cell activity were monitored simultaneously during the course of a series of habituating stimuli (see Materials and Methods). These motor neurons responded equally well to input from the left or right side of the tail, indicating that they receive sensory output from both sides of the animal. Eleven preparations were used. 
The results are shown in Figure 3. As in previous experiments, the tail-elicited siphon withdrawal response habituated significantly during the course of training (ANOVA: $F_{(29,290)}=10.85$, $p<0.001)$. Moreover, each stimulus also elicited a brisk discharge in the $\mathrm{LFS}_{\mathrm{B}}$ motor neurons (Fig. 3B). Thus, the threshold stimuli used in our earlier behavioral studies are capable of activating the motor neurons. During training, the number of action potentials in the barrage significantly decreased in parallel with the behavior (ANOVA: $\left.F_{(29,290)}=7.82, p<0.001\right)$ (Fig. $\left.3 B\right)$. This observation is consistent with reports that $\mathrm{LFS}_{\mathrm{B}}$ motor neurons participate in tail-elicited siphon withdrawal (Frost et al., 1988).

To characterize the tail motor neuron response during habituation, both siphon withdrawal responses and tail motor neuron activity were simultaneously observed during habituation training using stimuli identical to those used previously (Figs. 2, 3). We have already established that identical tail stimulation produces habituation of both siphon withdrawal and tail withdrawal (Fig. $2)$. Because siphon withdrawal is less subject to spontaneous movement than tail withdrawal in our preparation, siphon movement was used as a behavioral readout of habituation while cellular activity was recorded simultaneously.

As in the behavioral experiments, a series of 30 training stimuli were delivered to the tail at a $30 \mathrm{sec}$ ISI. Eleven preparations were used. Siphon withdrawal responses habituated significantly during training (ANOVA: $F_{(29,203)}=13.43, p<0.001$ ) (Fig. $4 A$ ). In parallel, the tail motor neurons also responded with progressively fewer action potentials (ANOVA: $F_{(29,203)}=14.68, p<0.001$ ) (Fig. 4B).

These results indicate that the $\mathrm{LFS}_{\mathrm{B}}$ siphon motor neurons and the pedal tail motor neurons both respond to the tail stimuli used in our behavioral studies, and that a progressive decrement in their responses closely parallels simultaneously measured habituation of the tail and siphon withdrawal reflexes.

\section{Tail sensory neuron responsiveness is modified during habituation}

We next examined whether the sensory neurons respond to tail input, and whether this response is modified by a series of 30 stimuli delivered at an ISI $(30 \mathrm{sec})$ that gives rise to habituation. These experiments were performed simultaneously as a subset of the tail motor neuron experiments described above (Fig. 4B). Six experiments were conducted; results are presented in Figure 5. During training, siphon withdrawal significantly habituated, as described earlier in the context of tail motor neuron responses (Fig. $4 A$ ) and as replotted in Figure $5 B$.

Three sensory neuron response characteristics were evident. (1) The duration of the barrage of sensory neuron action potentials was initially equal to the duration of the tail stimulus $(100 \mathrm{msec})$ (Fig. 5A) (this was also true for 50 and $200 \mathrm{msec}$ stimuli; data not shown). (2) As training proceeded, the sensory neuron responded with progressively fewer action potentials, from an average of $5.8 \pm 0.5$ spikes to $4.1 \pm 0.4$ spikes; ANOVA indicated a significant overall downward trend in spike number $\left(F_{(29,145)}=2.64\right.$, $p<0.001$ ) (Fig. 5A,C1). (3) The sensory neuron response latency grew progressively longer (measured from stimulus onset to the first spike in the barrage): the latency increased from an average of $280.2 \pm 18.8 \mathrm{msec}$ to $340.8 \pm 24.3 \mathrm{msec}$. ANOVA indicated a significant overall upward change in latency $\left(F_{(27,135)}=6.56, p<\right.$ 0.001 ) (Fig. 5A,C2). These results reveal that at least two forms of plasticity occur at the level of the primary sensory neuron response to habituating stimuli: (1) reduction of spike number and (2) increase in spike latency (Clatworthy and Walters, 1993) (also see Discussion). Both of these forms of plasticity seem consistent with the overall response decrement observed behaviorally and at the level of the complex EPSP in tail and siphon motor neurons.

\section{Synaptic analysis of habituation}

In the previous sections we characterized the responses of the motor and sensory components of the tail-induced tail and siphon withdrawal reflexes. Next we examined the synaptic output of the sensory neurons by monitoring the monosynaptic connection (Walters et al., 1983) between the sensory neurons and the tail motor neurons. By examining the responses of these cellular components during training that cause habituation of the reflex, we could test the hypothesis that sensory neuron homosynaptic depression contributes to habituation in the siphon and tail withdrawal systems.

We began the analysis by examining whether homosynaptic depression occurs at the monosynaptic connection between sensory neurons and tail motor neurons when the sensory neurons are activated repetitively (ISI $=30 \mathrm{sec}$ ) by intracellular current injection in a pattern that mimics the natural firing of the sensory neuron to tail stimulation (Fig. 5). A representative example of this experiment is shown in Figure 6, and a summary of our results from 10 such experiments is shown in Figure 7.

Similar amplitude pretest EPSPs were evoked by action potentials in control and "trained" (activated) sensory neurons. During repetitive activation, EPSP amplitudes from the trained cell diminished significantly (ANOVA for the initial depolarizing component of each EPSP: $\left.F_{(29,261)}=6.68, p<0.001\right)$. After training, synaptic output from both sensory neurons was tested. EPSPs evoked by action potentials in the control neurons were similar to their baseline amplitudes, as revealed by a planned test (dif = $-0.90 \pm 0.62 \mathrm{mV}, t_{(8)}=1.45$, NS); however, action potentials in the trained neurons elicited EPSPs significantly smaller than their own baseline amplitudes (dif $=-5.62 \pm 1.20 \mathrm{mV}, t_{(9)}=4.68, p<$ $0.002)$. Moreover, trained and control responses were significantly different from each other after training ( dif $=6.44 \pm 2.73 \mathrm{mV}, t_{(8)}$ $=2.36, p<0.05$ ) (Fig. 7).

The absence of significant response change in the control sensory neurons indicates that EPSP amplitude remains stable over time. Because EPSPs from both sensory neurons were monitored in the same postsynaptic neuron, it is likely that the source of EPSP decrement in the activated neuron was presynaptic. This experiment indicates that the tail sensory-to-motor neuron synapse undergoes homosynaptic depression when the presynaptic sensory neuron is fired repetitively with intracellular current in a pattern like that generated by tail-stimulation training. Similar results have been obtained previously using single-spike intracellular activation (Walters et al., 1983; Buonomano et al., 1992).

This experiment, however, does not address the effect of repetitive activation by tail stimulation on the output of the sensory neurons. In the previous experiment, only the "trained" sensory neuron was activated directly during training. When the tail is stimulated, however, many more neurons (other sensory neurons and interneurons) are involved as well. To examine whether homosynaptic depression occurs under these conditions, we trained with a series of threshold tail stimuli, just as in the behavioral studies. We simultaneously measured the complex EPSP evoked in the tail motor neuron as well as a behavioral response, siphon withdrawal.

The procedure (see Materials and Methods) and representative responses are illustrated in Figure 8. Six animals were used. After habituation training, rather than exhibiting depression, the mono- 


\section{A. Siphon \\ Behavior}

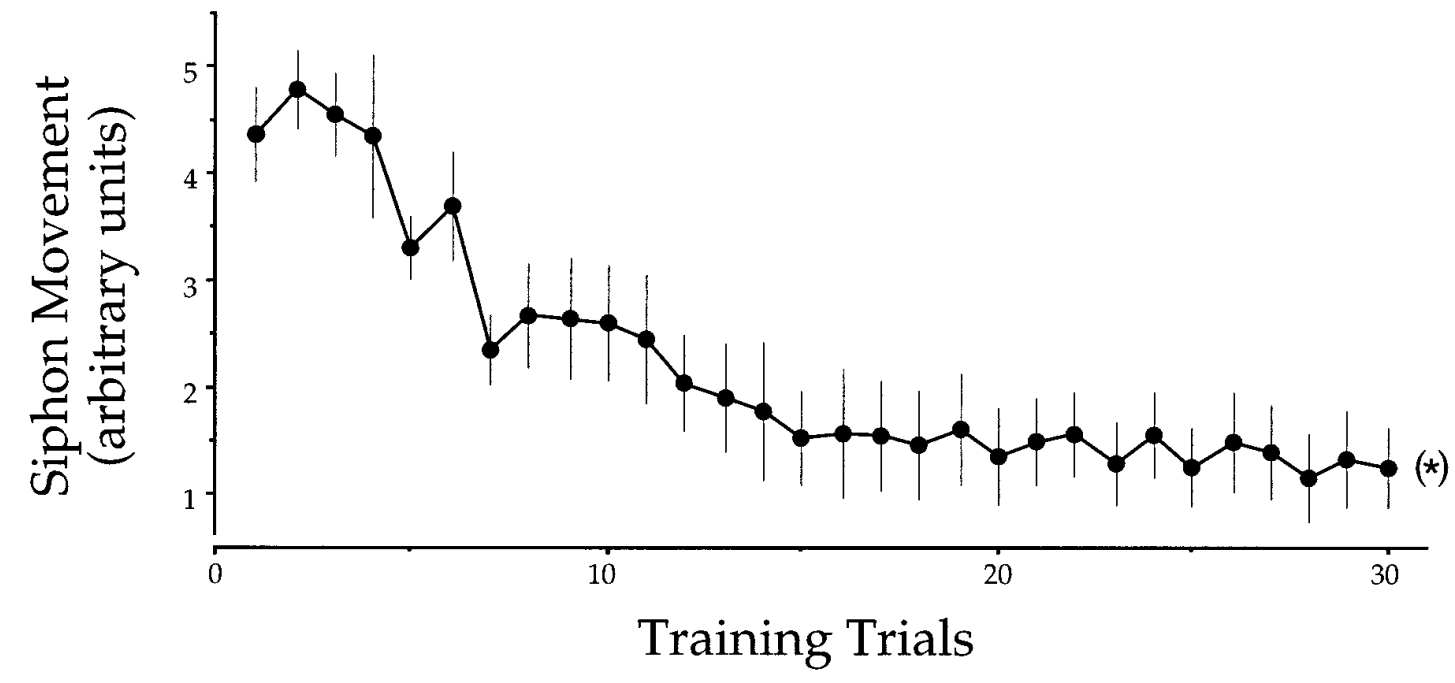

B. Tail Motor
Neuron

Trial 1
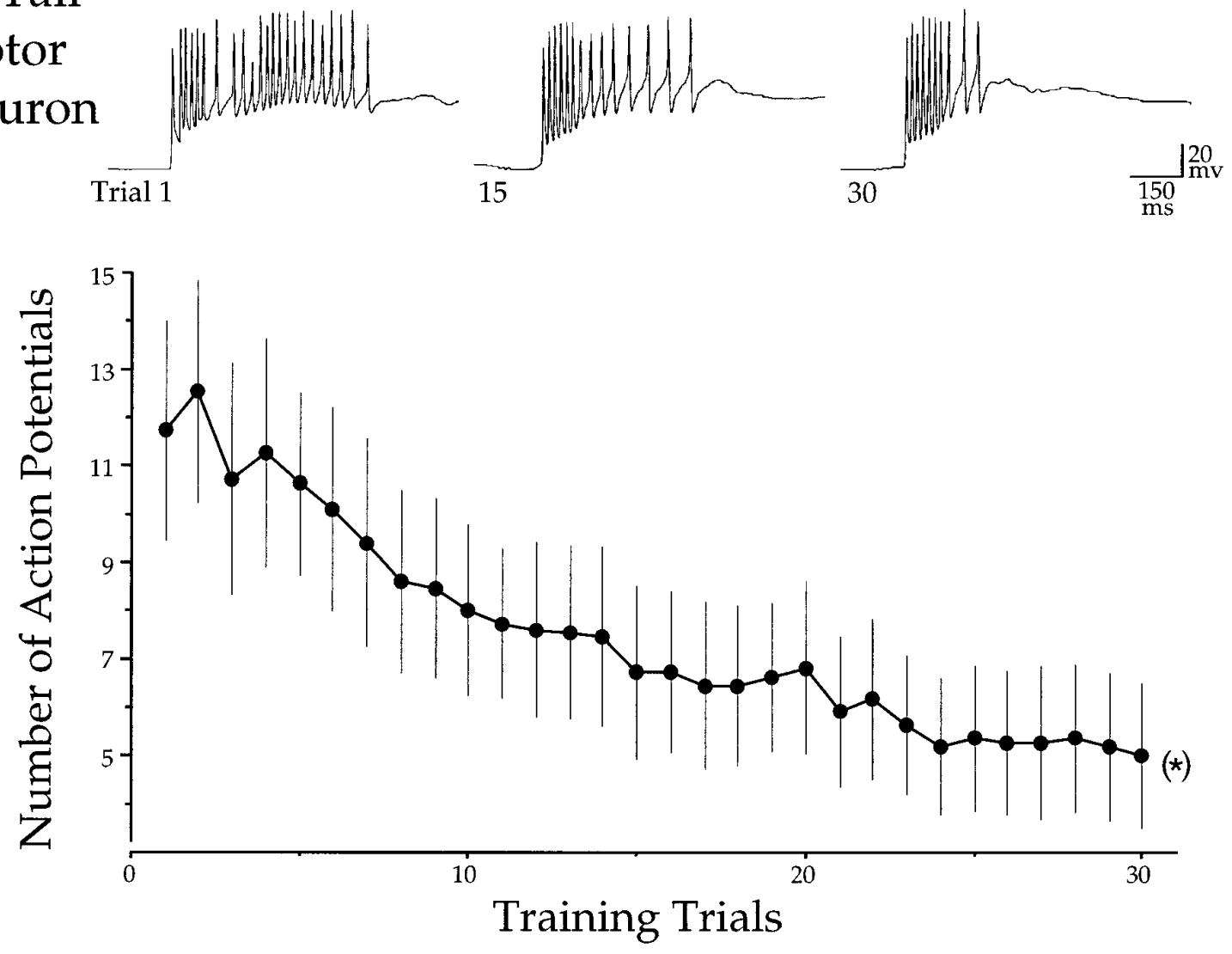

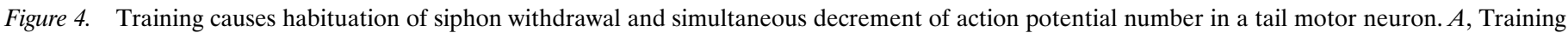

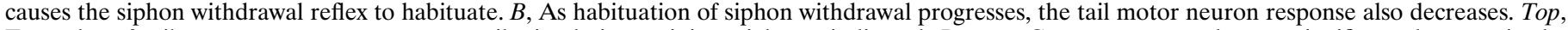

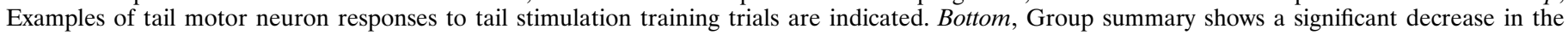
number of action potentials per response over trials. See legend to Figure 2 for statistical significance indicated by asterisks. 


\section{A. Tail Sensory Neuron}

Trial 1

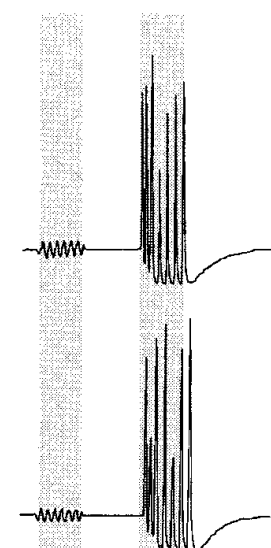

10

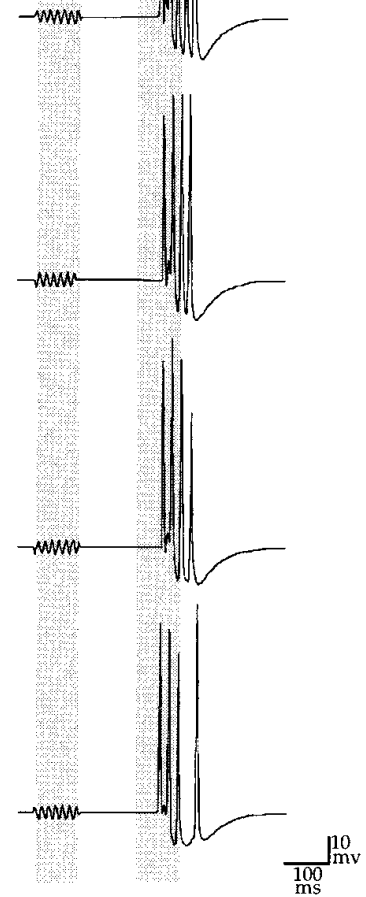

B. Siphon Behavior

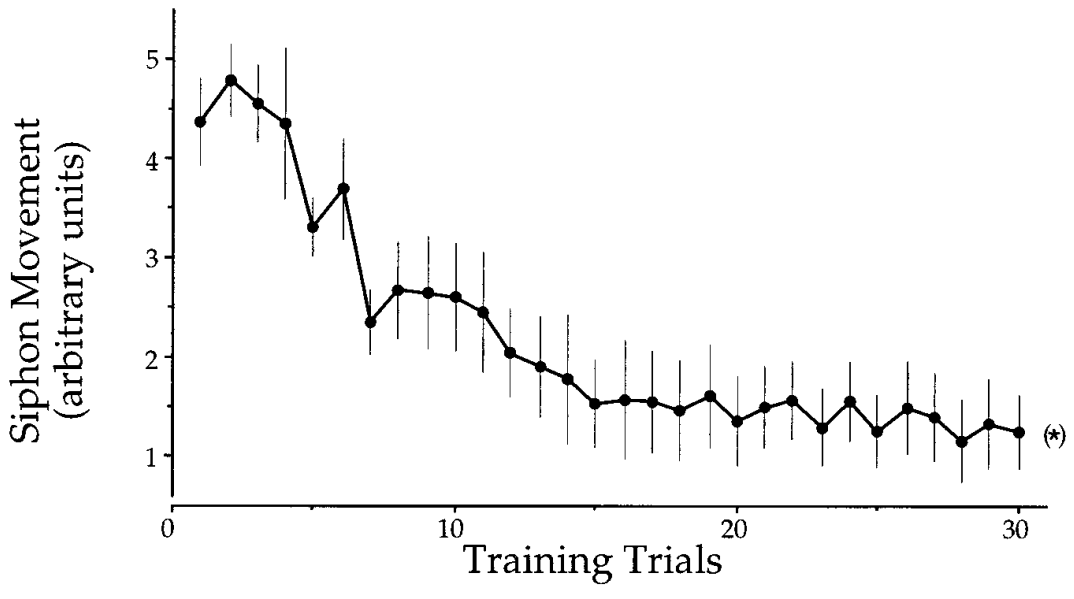

$\mathrm{C}_{1}$. Number of Spikes per Barrage

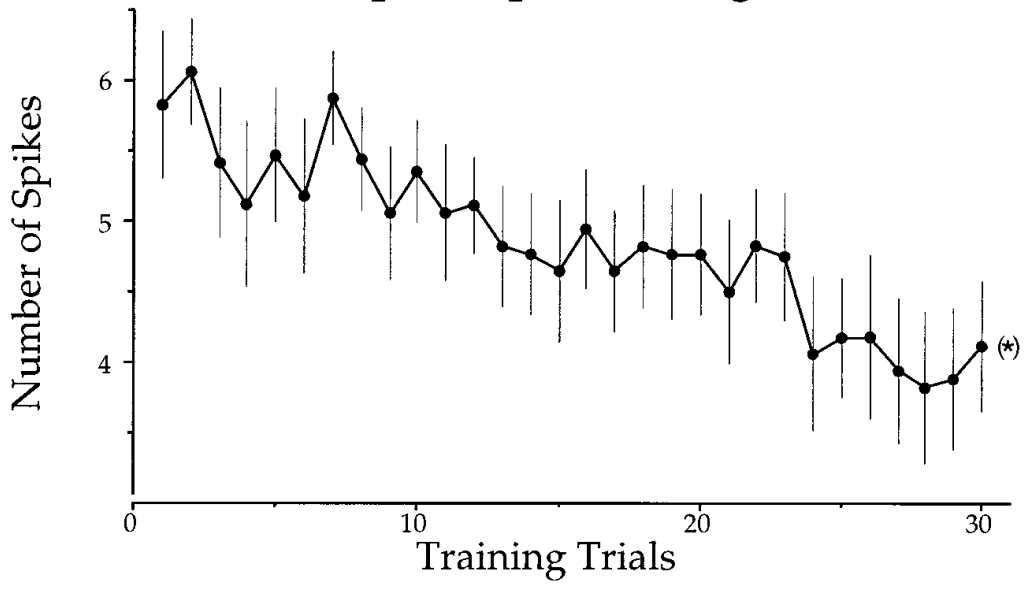

$\mathrm{C}_{2}$. Barrage Latency

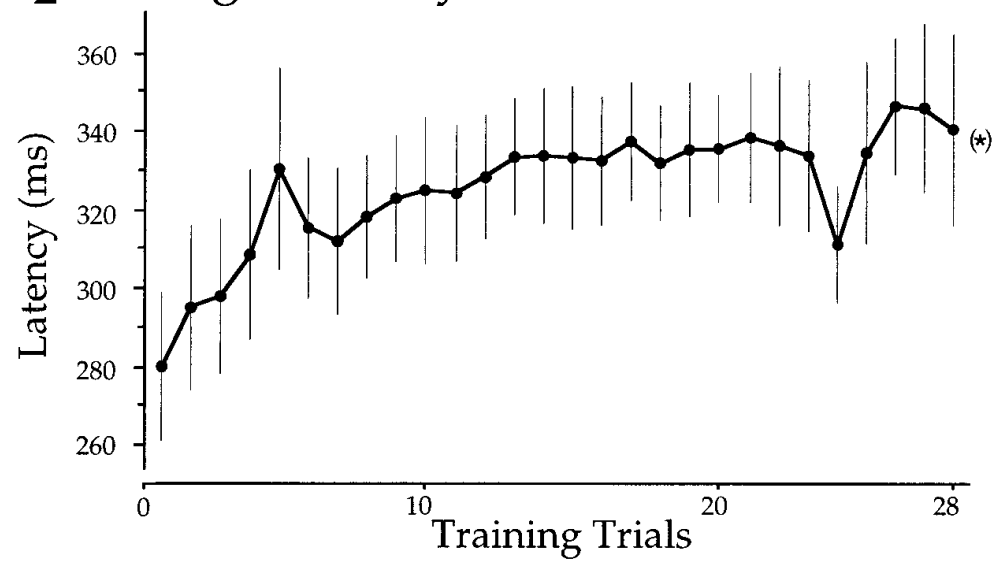

Figure 5. Tail sensory neuron responses are altered by habituation training. $A$, Representative sensory neuron responses to training by weak tail shock. Shaded vertical bars illustrate that (1) action potential barrage is of the same duration as the stimulus pulse (first bar encompasses the stimulus artifact) and (2) sensory neuron response latency increases during training. Note also the reduction in spike number (see below). $B$, Siphon withdrawal habituates during training. Siphon responses were monitored together with cellular responses, and for clarity are replotted here from Figure $4 A$. $C 1$, Group data show that during training, the number of sensory neuron action potentials per barrage decreases significantly. $C 2$, Group data show that during training the sensory neuron response latency, measured from stimulus onset to response onset, increases significantly. See legend to Figure 2 for statistical significance indicated by asterisks. 


\section{Pre-test}

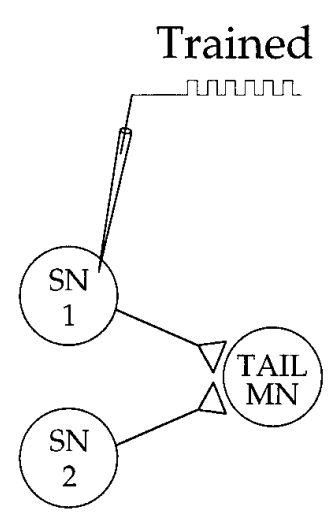

\section{Control}
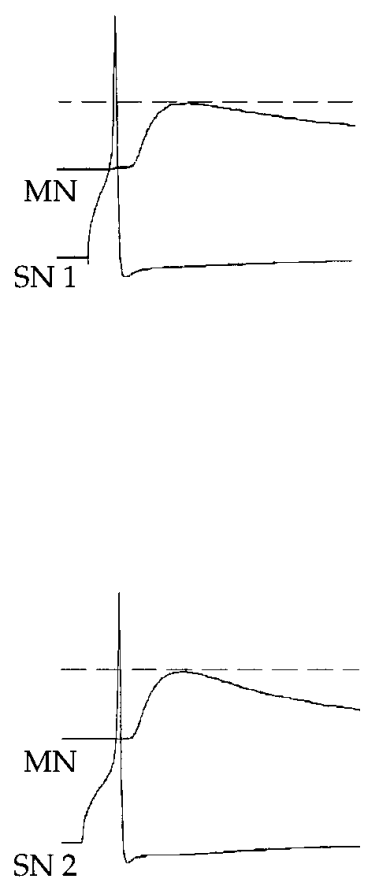

Intracellular Training

\section{Test (5 min)}

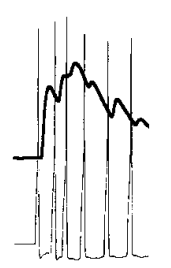

Trial 1

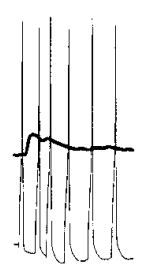

15

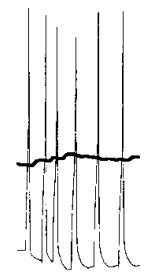

30
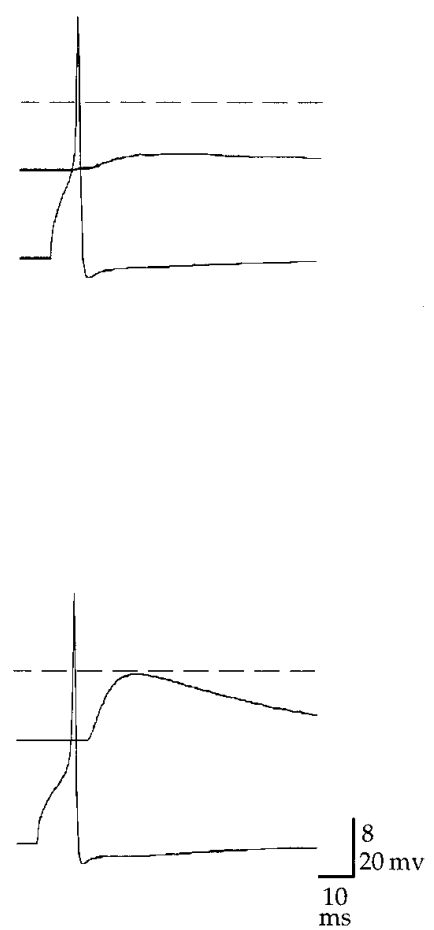

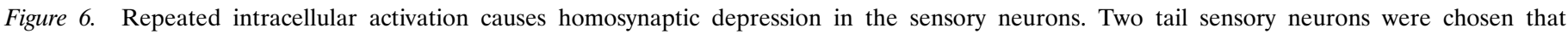

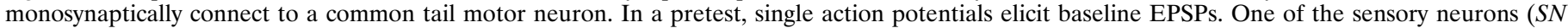

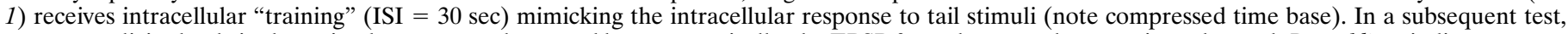

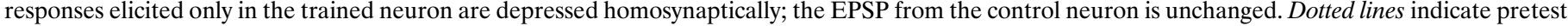
EPSP amplitude.

synaptic EPSP from the trained (activated) sensory neuron actually is increased substantially. Likewise, the EPSP from the control (nonactivated) sensory neuron is also clearly increased, indicating that the increased EPSP observed in both sensory neurons is likely attributable to heterosynaptic facilitation. Thus, these results are qualitatively different from those obtained when repeated activation of the sensory neuron is accomplished by intracellular activation of the sensory neuron (Figs. 6, 7).

A summary of the results is shown in Figure 9. As expected, training caused significant habituation of the siphon withdrawal response (ANOVA: $F_{(29,145)}=13.43, p<0.001$ ) (Fig. 9B). At the same time, during the course of training, the complex EPSPs recorded in the tail motor neuron also decreased significantly (ANOVA: $F_{(29,145)}=9.34, p<0.001$ ) (Fig. $9 C$ ). Simultaneously, however, the monosynaptic EPSPs evoked by single spikes in the sensory neurons (intercalated between tail stimuli; see Materials and Methods) increased significantly in amplitude during the course of the training (ANOVA: $F_{(29,145)}=5.24, p<0.001$ ) (Fig. $9 A$ ). EPSPs from sensory neurons that were activated by the tail stimuli remained significantly elevated above their baseline levels for the entire duration of the training session (post-hoc NewmanKeuls tests for each training response, $p<0.01)$. A series of monosynaptic EPSP tests were made 1, 5, and 10 min after training. EPSP amplitudes remained elevated above baseline after the conclusion of training (Newman-Keuls test for 1 min test, $p<0.01)$.

The dissociation between the behavioral response and the complex EPSP in the motor neuron on the one hand, and the mono- synaptic EPSP on the other hand (Fig. 9), was unexpected. Therefore, the experiment was replicated with two differences: single monosynaptic EPSPs were not elicited between tail stimuli during training, thus eliminating the potential confound of repeated intracellular activation, which could by itself produce some homosynaptic depression in the tail sensory neurons. EPSP tests were made only after the conclusion of training. Also, instead of monitoring siphon movement directly, extracellular recordings were made from the siphon nerve as an analog of the behavioral response.

The results are shown in Figure 10. Fifteen experiments were conducted. Because of the experimental design, it was not possible to counterbalance the prescores; by chance, pretest EPSPs in the trained sensory neuron group were slightly larger $(\sim 2 \mathrm{mV}$ on average) than in control sensory neurons, but the difference was not statistically significant. After the pretest, threshold-level habituation training stimuli (30 stimuli delivered at a $30 \mathrm{sec}$ ISI) were presented to the tail. During training, the number of spikes recorded extracellularly in the siphon nerve significantly decreased (from an average of $104.9 \pm 41.0$ spikes to $40.3 \pm 8.1$ spikes; ANOVA: $\left.F_{(29,406)}=6.47, p<0.001\right)$. This decrement in siphon nerve output, illustrated in Figure $10 B$, is consistent with the habituation of the siphon withdrawal reflex observed in other experiments (Figs. 2A, 9B).

After training, a series of monosynaptic EPSP tests was conducted, as above (Fig. 9). Again, training caused a significant increase in monosynaptic EPSP amplitude when EPSPs were evoked from either trained sensory neurons (those activated by 


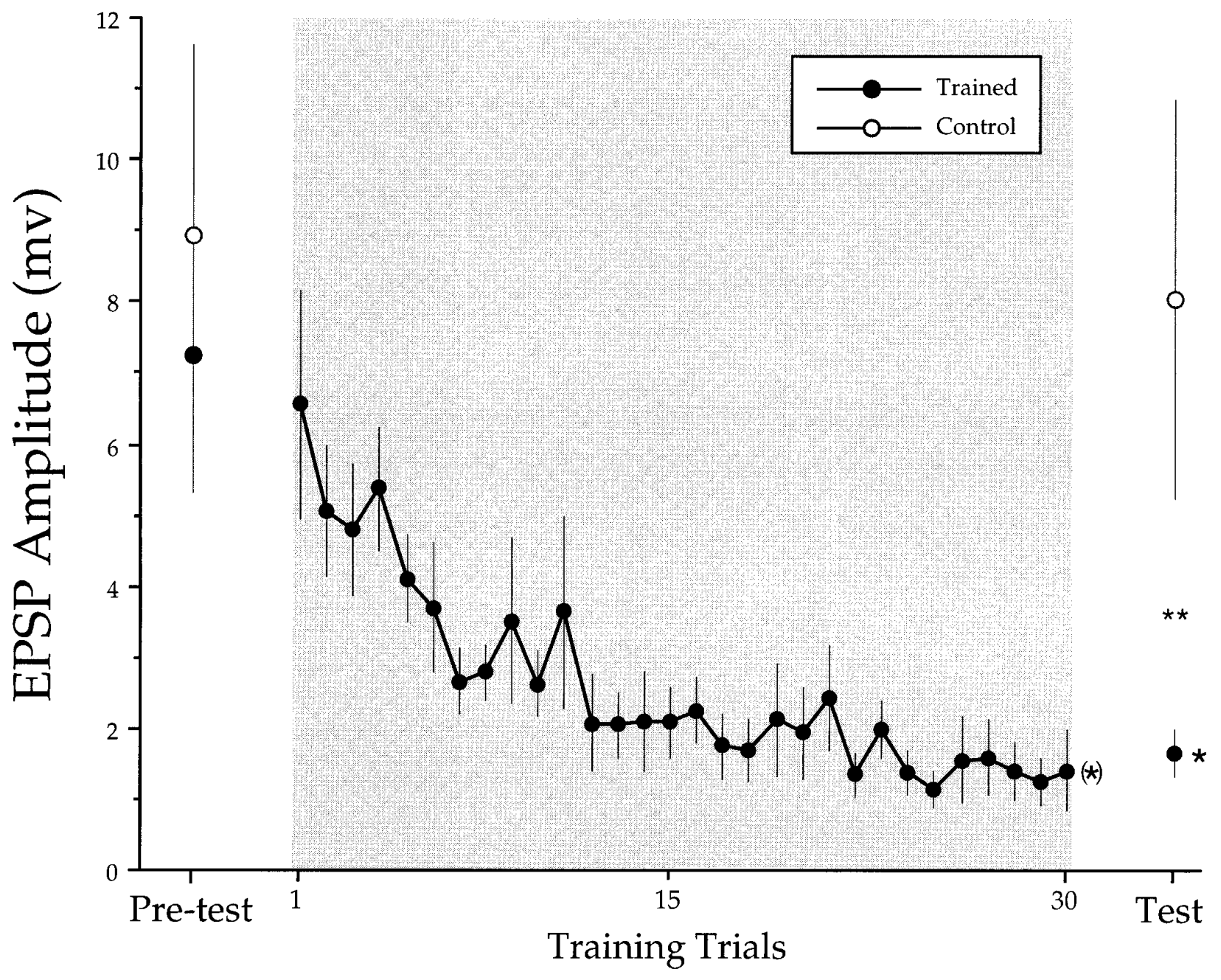

Figure 7. Summary of results illustrating homosynaptic depression produced by intracellular activation of sensory neurons. EPSPs elicited from "trained" sensory neurons exhibit significant decrement during, and $5 \mathrm{~min}$ after, training. (Responses during training are indicated by shading.) The amplitude of only the initial EPSP was measured. EPSPs elicited from control sensory neurons remain unchanged from baseline. See legend to Figure 2 for statistical significance indicated by asterisks.

the tail stimulus) or control sensory neurons (those outside the receptive field of the tail stimulus and thus not activated) (ANOVA for pretests and tests: $F_{(7,98)}=14.33, p<0.001$; there was no significant interaction by group: $F_{(7,48)}=0.45$, NS) (Fig. $10 A$ ). Subsequent post-hoc comparisons revealed that both trained and control EPSPs remained significantly greater than baseline for several minutes after training (Newman-Keuls: 1 min and 5 min after training, $p<0.01$ ) for trained and controlled cells. Moreover, the EPSPs from trained neurons remained elevated above baseline longer than those from control neurons.

Our results, taken together, indicate that there is a dissociation between response decrement during habituation in tail withdrawal and siphon withdrawal reflexes, and response facilitation of the monosynaptic EPSP generated by sensory neuron activity. Specifically, during habituation, at the same time that significant decrement occurs in the behavioral responses in each system, as well as in the complex EPSPs and spike output in the motor neurons for each system, significant facilitation occurs in the monosynaptic EPSP from the tail sensory neurons.

\section{DISCUSSION}

Habituation is often described as the simplest, most basic form of learning, and yet surprisingly little is known about how it is mediated by the nervous system. One seminal hypothesis proposes that during the course of habituation, repetitively activated primary sensory neurons undergo the process of homosynaptic depression. From this perspective, the sensory neurons are thought to release progressively less transmitter with each successive stimulus, thereby contributing progressively less input to interneurons and motor neurons mediating the behavior (Krasne, 1969; Castellucci et al., 1970; Zucker, 1972; Castellucci and Kandel, 1974; Hawkins et al., 1993). The capacity of sensory neurons to exhibit homosynaptic depression is well documented in Aplysia and other preparations (Krasne, 1969; Castellucci et al., 1970; Zucker, 1972; Klein et al., 1980; Byrne, 1982); however, the role of homosynaptic depression in mediating the behavioral decrement of habituation has been studied only in the gill and siphon withdrawal reflex elicited by siphon stimulation.

In this study, we examined two reflex systems activated by tail stimulation. One, the tail withdrawal reflex, appears comparable to the gill and siphon withdrawal reflex (elicited by siphon stimulation) in that it has both monosynaptic and polysynaptic connections to tail motor neurons; the other, the siphon withdrawal reflex, appears somewhat more complex because it has only polysynaptic connections to motor neurons. We show that repet- 
Pre-test

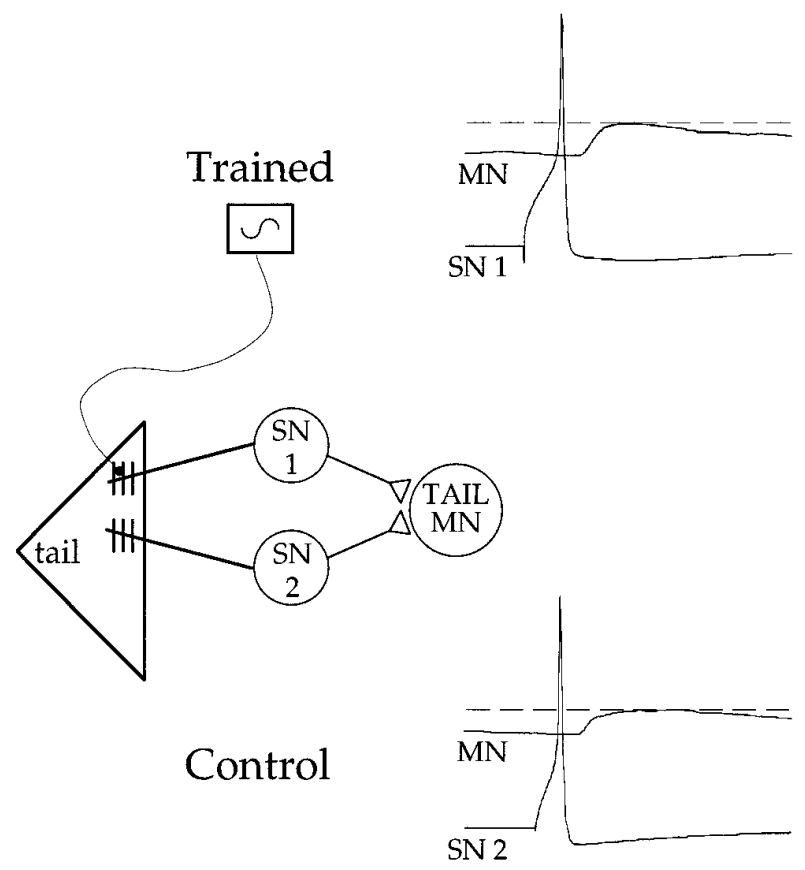

Habituation Training

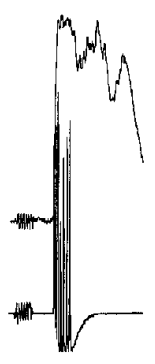

Trial 1

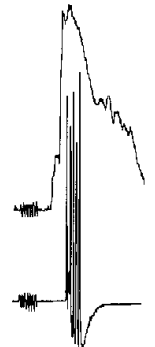

15

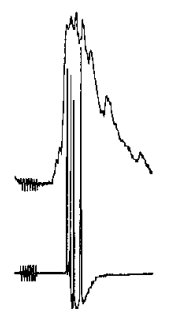

30
Test (5 min)

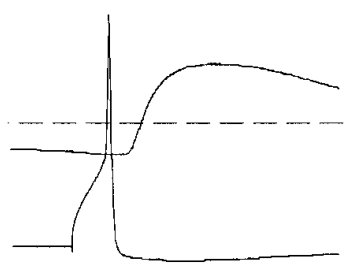

$\overline{150}$

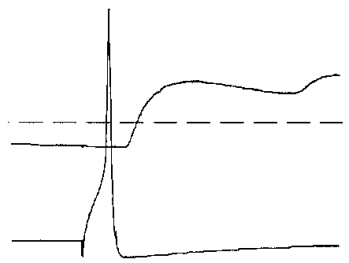

Figure 8. Heterosynaptic facilitation occurs in tail sensory neurons during habituation. Two tail sensory neurons were chosen that monosynaptically connect to a common tail motor neuron. In a pretest, single action potentials elicited baseline EPSPs. Only one of the sensory neurons ( $S N$ 1) was activated by habituation training stimuli (ISI $=30 \mathrm{sec}$ ) from a tail electrode implanted within its receptive field (note compressed time base). The other sensory neuron $(S N 2)$ was not activated by the tail stimulus. After training, monosynaptic EPSPs elicited by both sensory neurons were facilitated significantly.

itive, threshold-level tail stimuli cause both the tail-elicited tail and siphon withdrawal reflexes in reduced preparations to exhibit habituation comparable with that observed in intact animals (Stopfer and Carew, 1994; Stopfer et al., 1996). These same tail stimuli simultaneously cause several different forms of modulation at different sites in the neural circuits underlying these reflexes. For example, (1) during repeated stimulation, the motor neurons that contribute to tail withdrawal and those that contribute to siphon withdrawal both generate progressively fewer action potentials. (2) The sensory neurons that we recorded from, which respond to the tail stimuli, also generate progressively fewer action potentials, and they respond with increasing latency to each stimulus. A similar decrease in spike number and increase in response latency in tail sensory neurons has been observed after noxious, repetitive tail stimulation (Clatworthy and Walters, 1993). These authors refer to the action potential number and latency changes collectively as response "wind-down." The present findings indicate that the same wind-down mechanisms can be evoked by weak stimuli as well. (3) When the sensory neurons are fired intracellularly in a pattern like that caused by tail stimulation, they exhibit marked homosynaptic depression. (4) At the same time that the behavioral and motor neuronal responses exhibit decrement during habituation training, synaptic transmission from the sensory neurons actually increases substantially. These results indicate that alterations in spike number and spike latency in the sensory neurons might contribute to habituation in the siphon withdrawal and tail withdrawal reflexes elicited by tail stimulation (although these response reductions appear modest in magnitude compared with the accompanying heterosynaptic facilitation). These results also show that homosynaptic depression in the sensory neurons does not accompany habituation, suggesting instead an important role for interneurons in producing this simple form of learning.

The possibility might be raised that the reason that sensory neurons show synaptic facilitation during repeated tail stimulation is that the eliciting tail stimulus is a strong one, actually serving at least in part as a sensitizing stimulus. This possibility is unlikely for two reasons. First, the strength of the tail stimulus was chosen to be just threshold for activation of both the reflexes that we examined; if the stimulus were any weaker, no behavior would be reliably elicited. Second and more compelling is the fact that in both reflexes the behavioral response (as well as the input to the motor neurons) exhibited progressive and significant decrement during repeated stimulation. Thus, at a functional level, the tail stimulus in our experiments cannot be considered facilitatory 


\section{A. Monosynaptic EPSP}

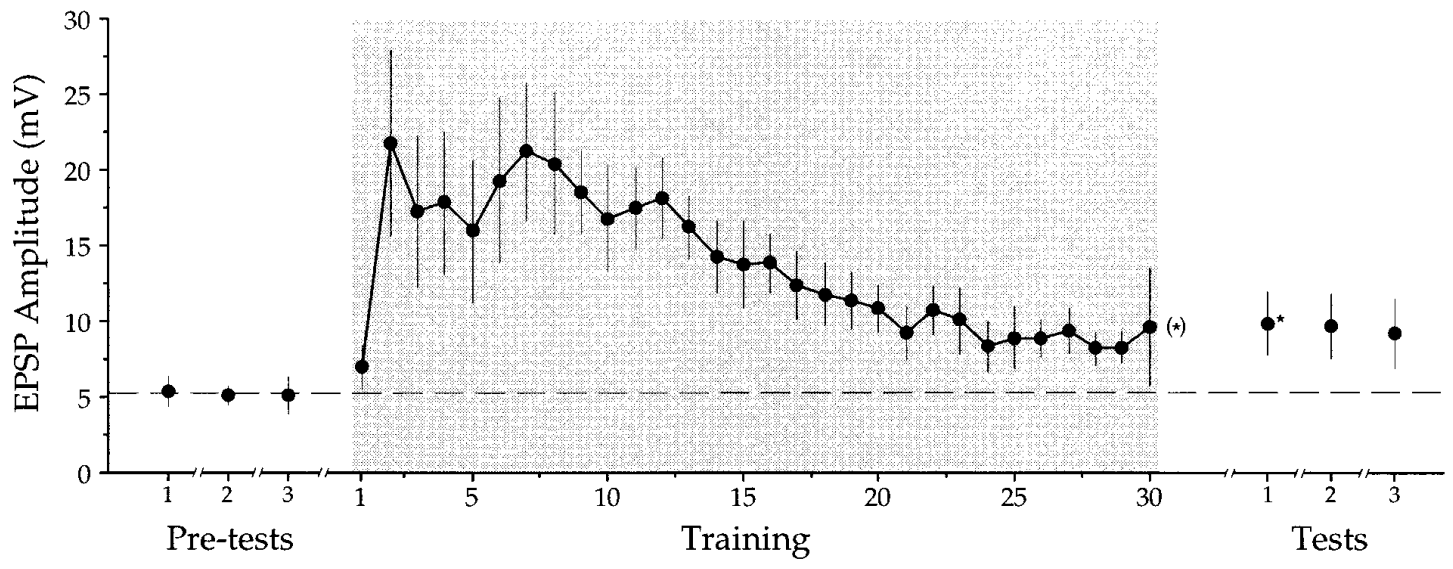

\section{B. Siphon Behavior}

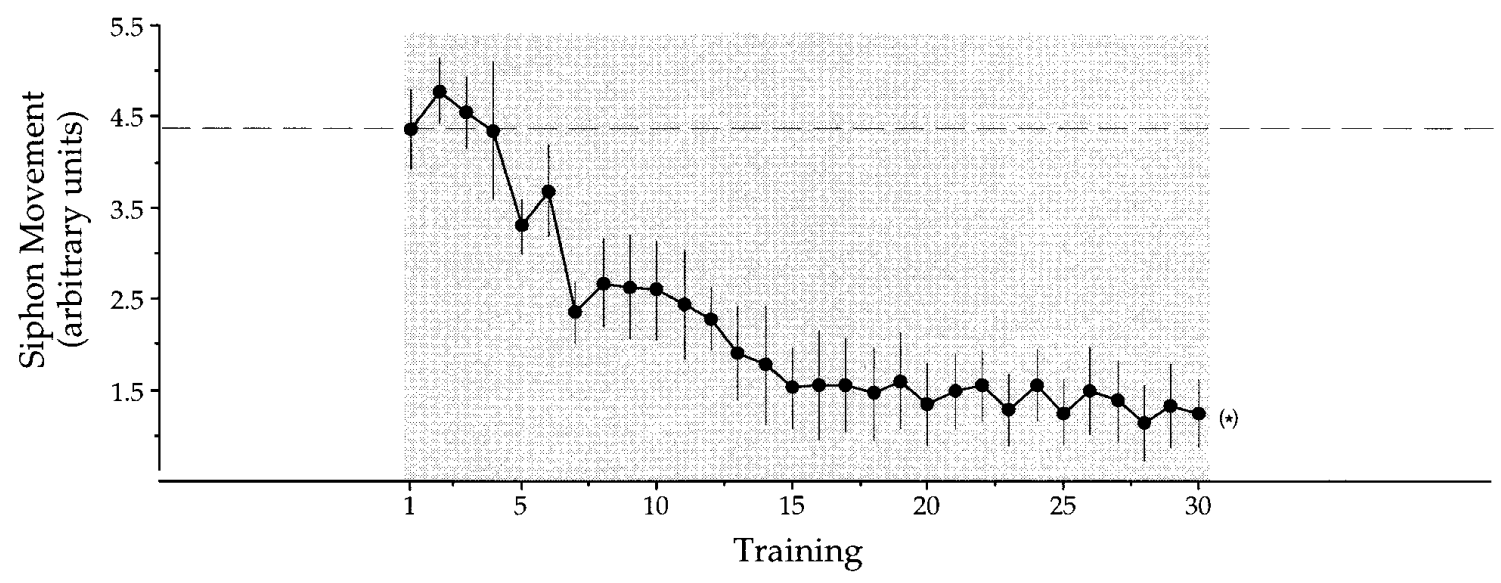

\section{Complex EPSP in Tail Motor Neurons}

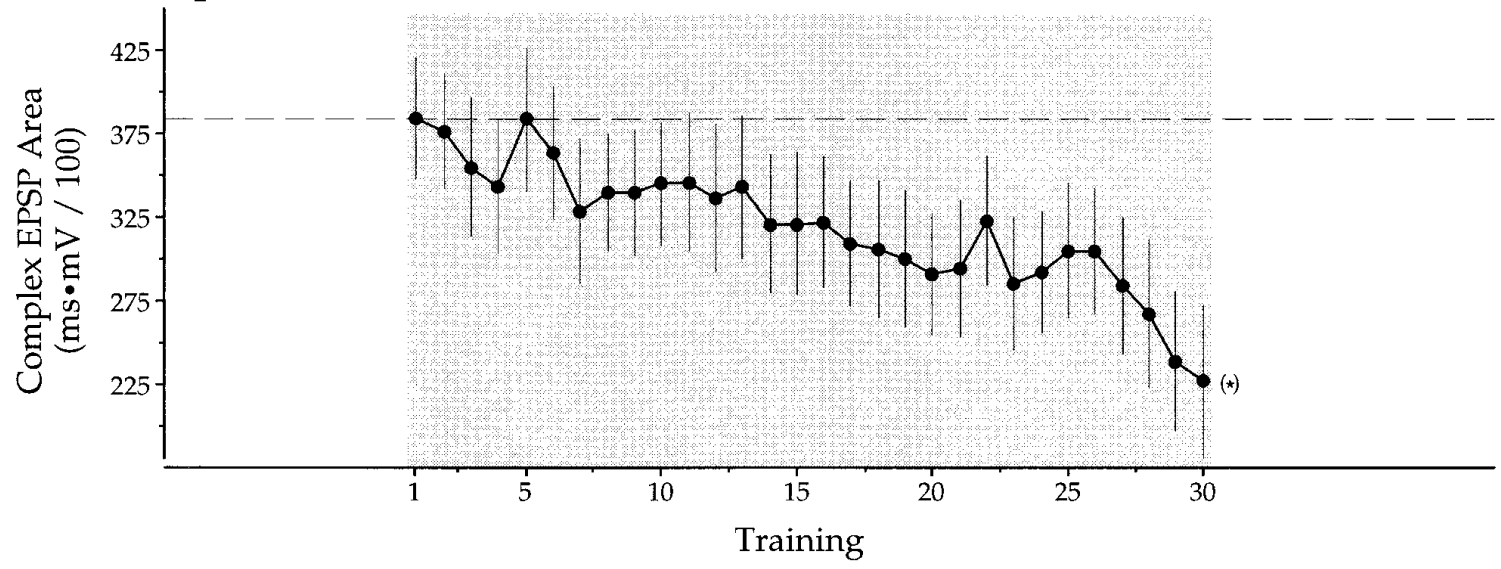

Figure 9. Habituation training facilitates sensory neuron synaptic transmission while simultaneously producing behavioral and motor neuronal decrement. $A$, Monosynaptic EPSPs from tail sensory neurons onto tail motor neurons were facilitated significantly over baseline response levels during training (shaded area). Pretests were conducted 15, 10, and $5 \mathrm{~min}$ before training. Intracellularly stimulated post-tests were conducted 1,5 , and 10 min after training. $B$, Replotted from Figure $4 A$. During training (shaded areas), the simultaneously monitored siphon withdrawal reflex habituated significantly, and $(C)$ the complex EPSP recorded in the tail motor neurons also decremented significantly. (Dashed lines $=$ initial response levels.) Tail stimulus pre- and post-tests were not delivered because they would have confounded the intracellular tests (see $A$ ) by facilitating the synapse. See legend to Figure 2 for statistical significance indicated by asterisks. 


\section{A. Monosynaptic EPSP}
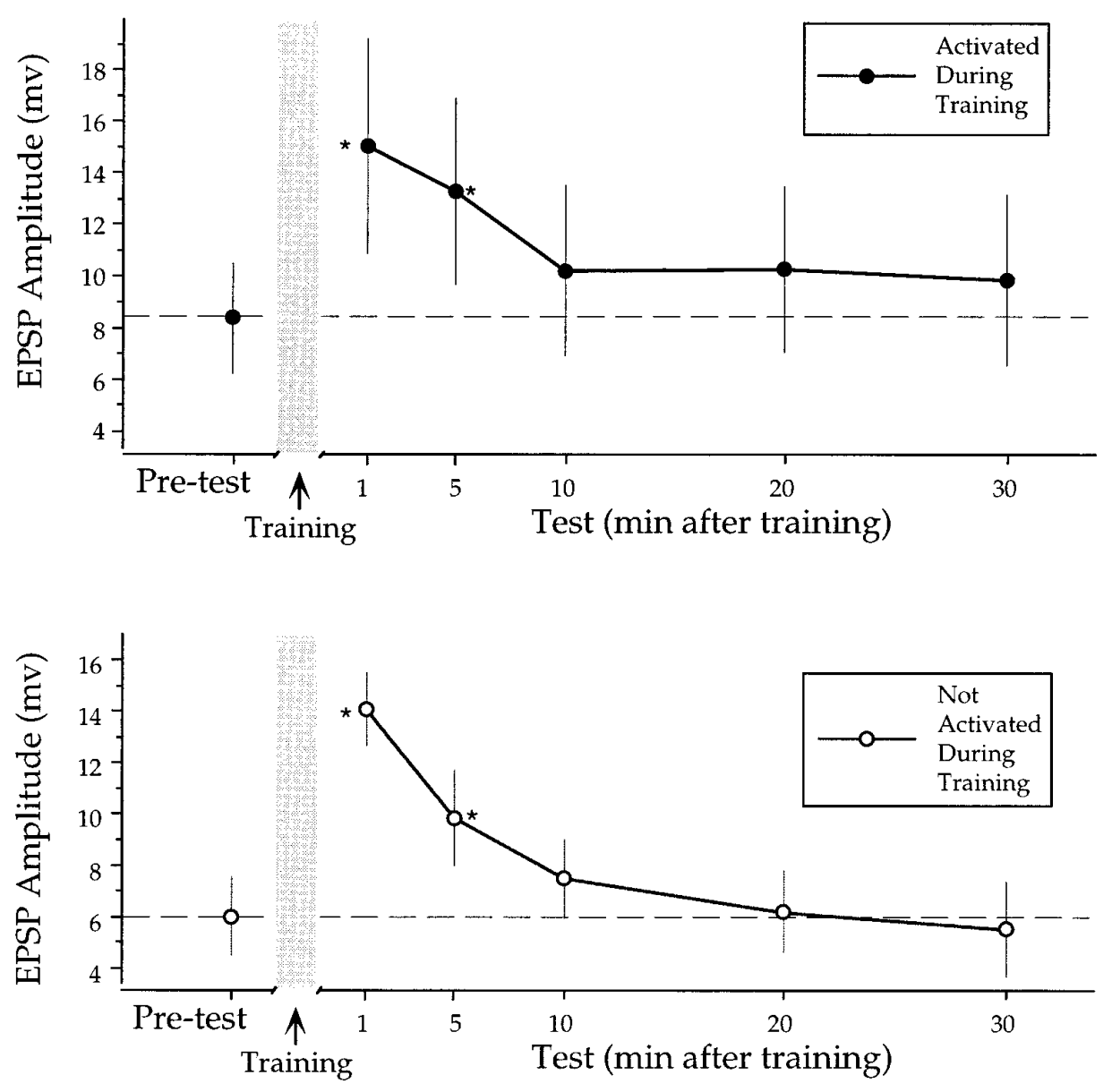

\section{B. Motor Output}

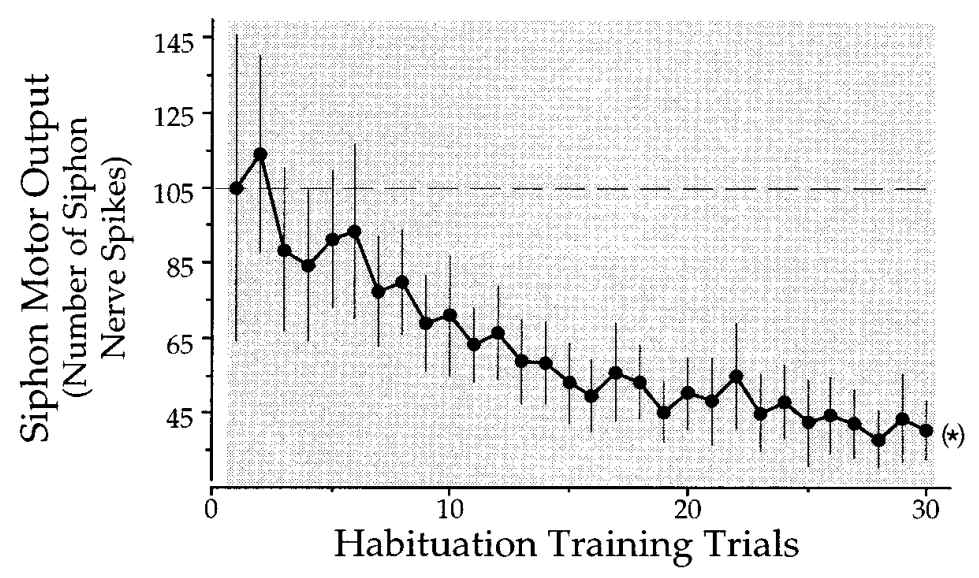

Figure 10. Habituation training causes heterosynaptic facilitation of tail sensory-motor neuron synapses. $A$, After training (indicated by shaded area, see $B$ ), tail sensory neurons activated during training (top) as well as not activated during training (bottom) exhibited monosynaptic EPSPs that were facilitated significantly above pretest amplitude (indicated by dashed lines). $B$, During training, the number of action potentials recorded from the siphon nerve (an extracellular readout of siphon withdrawal) decreased significantly below its initial level (indicated by dashed line). See legend to Figure 2 for statistical significance indicated by asterisks. 
because its repeated application produces only significant habituation.

A final comment concerning the role of tail sensory neuron synaptic depression in habituation is warranted. Our data do not rule out the possibility that under different experimental conditions (e.g., different patterns, durations, or intensities of afferent activation), homosynaptic depression might be induced in the sensory neurons and thus could contribute to habituation of tail-mediated reflex responses. Similarly, our data do not exclude the possibility that during habituation, homosynaptic depression might occur at synapses (1) from an unidentified population of tail sensory neurons or (2) between the identified tail sensory neurons and interneurons, and that this depression occurs even as other synapses between the same identified sensory neurons and motor neurons show clear facilitation (it should be pointed out that this latter case, although possible, has never been observed in Aplysia; see Trudeau and Castellucci, 1993; Clark and Kandel, 1984). Nevertheless, our results do permit the conclusion that homosynaptic depression in the identified tail sensory neurons is not necessary for habituation because we have shown that significant reflex habituation (as well as decrement in the input to and output from motor neurons) can occur in the absence of homosynaptic depression in the tail sensory neurons.

\section{The contribution of homosynaptic depression to habituation in other systems}

Homosynaptic depression in primary sensory neurons has been directly implicated as a mechanism contributing to habituation in two other systems: the gill withdrawal reflex of Aplysia to siphon stimulation and the tail-flip escape response of the crayfish. We will discuss each of these systems in turn.

\section{Habituation in the gill withdrawal reflex}

The possible role and site of homosynaptic depression during habituation in Aplysia was investigated initially in the siphonelicited gill withdrawal reflex (Castellucci et al., 1970; Kupfermann et al., 1970; Pinsker et al., 1970; Carew et al., 1971). This work supported the conclusion that homosynaptic depression at the LE siphon sensory neurons underlies the response decrement observed in the behaving animal. Thus, these conclusions differ from those obtained in the present studies.

It is possible that methodological differences between the gill withdrawal experiments and those reported here are responsible for the different conclusions reached regarding homosynaptic depression. For example, in the experiments examining the gill withdrawal reflex (Castellucci et al., 1970), a different kind of eliciting stimuli (water jets to the siphon) was used; a different motor response (gill withdrawal) was monitored, and the monosynaptic connection between LE sensory neurons and motor neurons was not examined concurrently with habituation of gill withdrawal behavior. It is also possible that different forms of plasticity at different neuronal sites may contribute to habituation in the gill withdrawal system compared with the reflex systems we describe in this paper. This may be the case because the reflexes have some clear differences in their cellular organization. For example, although the tail-induced tail withdrawal reflex is similar to the gill withdrawal reflex in that there is direct monosynaptic input (as well as polysynaptic input) to tail motor neurons from tail sensory neurons, the tail-induced siphon withdrawal reflex does not have such a direct sensory input to siphon motor neurons. Tail sensory input to siphon motor neurons seems to be entirely polysynaptic (Cleary and Byrne, 1993). Thus, differing reflex architecture, at least in tail-induced siphon withdrawal, may also underlie differences in the two systems. In future studies it will be of interest to carry out directly comparable experiments in reflexes mediated by tail and siphon sensory neurons to explore the role of homosynaptic depression in habituation in these two different sensory systems.

Another study examining homosynaptic depression in LE siphon sensory neurons may provide some insight into the threshold for the facilitatory processes we observe in the tail sensory neurons during repeated tail stimulation. In studying synaptic plasticity in the siphon withdrawal reflex, Wright et al. (1991) simultaneously examined decremented complex EPSPs in siphon motor neurons produced by repeated water jet stimuli to the siphon and in decremented monosynaptic EPSPs from LE siphon sensory neurons onto the same motor neurons. The decrement in the siphon sensory neurons was produced by repeated intracellular activation of the sensory cells, intercalated between water jet stimuli to the siphon. In this study, the water jet stimuli to the siphon were too weak to activate the LE siphon sensory neurons; thus the tactile input to the siphon motor neurons was probably carried by another set of low-threshold afferents from the siphon (Kaplan et al., 1993). In the Wright et al. (1991) study, heterosynaptic facilitation was not produced by repeated water jet stimuli to the siphon (which were subthreshold for LE siphon sensory neuron activation). In this study, however, heterosynaptic facilitation was produced by tail stimuli that were selected specifically to be just above threshold for tail sensory neuron activation. This suggests that the heterosynaptic facilitatory process we observe may have a stimulus threshold comparable to that required for sensory neuron activation. It would therefore be of interest in the gill and siphon withdrawal system to determine whether the stimulus threshold necessary for reflex activation of the LE siphon sensory neurons (e.g., by tactile or electrical stimulation of the siphon skin) would also be the threshold for activation of a facilitatory process that would produce heterosynaptic facilitation of EPSPs from these siphon sensory neurons. Of relevance to this point, recent preliminary results by Hawkins and colleagues (personal communication; see also Hawkins and Frost, 1995; Hawkins and Frost, in press) suggest that habituation of the gill withdrawal reflex induced by tactile stimulation of the siphon in a simplified preparation is accompanied by homosynaptic depression of EPSPs from LE sensory neurons, which parallels decrement of siphon-evoked complex EPSPs in siphon motor neurons.

\section{Habituation in the tail-flip response of crayfish}

In the crayfish, tail-flip escape responses mediated by the lateral giant fibers exhibit habituation when the mechanosensitive primary afferents mediating the reflex are activated repeatedly (Wine et al., 1975). Several studies have shown that with repeated activation of this afferent input, homosynaptic depression occurs at the first chemical synapse in the reflex pathway, giving rise to the hypothesis that homosynaptic depression at this synapse may provide the cellular mechanism of habituation in this system (Krasne, 1969; Zucker et al., 1971; Zucker, 1972). As recently pointed out by Krasne and Teshiba (1995), all of the experiments examining homosynaptic depression in the crayfish were carried out in acute, surgically reduced preparations that did not permit descending modulatory influences from higher brain centers to be expressed. Recently, Krasne and colleagues (Krasne, 1993; Krasne and Teshiba, 1995) reexamined the mechanisms of habituation in freely behaving, intact crayfish and found that the predominant mechanism for habituation involves descending 
tonic inhibition from higher brain centers. Homosynaptic depression at the primary afferent synapse was found to have only a modest impact on habituation in intact animals. Thus, these recent observations in the crayfish are consistent with our observations that homosynaptic depression of primary afferent synaptic transmission, at least in the reflexes we have examined, may be of less importance than changes at interneuronal sites during habituation.

\section{Additional sites and mechanisms of habituation}

Our finding that a reduction in synaptic transmission in tail sensory neurons does not accompany habituation shifts the focus onto interneurons in the reflex circuits (Hawkins et al., 1981; Cleary et al., 1995; Frost and Kandel, 1995). In the case of tail-elicited siphon withdrawal, interneurons fully mediate sensory-to-motor communication (Cleary and Byrne, 1993). In the case of tail-elicited tail withdrawal, interneurons provide a powerful, parallel pathway that seems to influence behavior more strongly than does the direct, monosynaptic pathway (Cleary and Byrne, 1993; White et al., 1993).

Two major candidate mechanisms can be envisioned as playing a significant role in mediating habituation at interneurons: homosynaptic depression and increased inhibition (of course, these two possibilities are not mutually exclusive). We have already considered the evidence that homosynaptic depression occurs at Aplysia central synapses. Thus, this form of decremental plasticity at any interneuronal site is a reasonable candidate to contribute to habituation.

Inhibition is also well described in reflex circuits in Aplysia, and many authors have speculated that this process may play a role in habituation of both siphon- and tail-elicited responses (Montarolo et al., 1988; Schacher and Montarolo, 1991; Wright et al., 1991; Buonomano et al., 1992; Fischer and Carew, 1993). Thus, the buildup of inhibition (possibly driven in part by the facilitation of the sensory neuron output during habituation that we observe) at interneuronal sites is certainly a reasonable candidate mechanism for habituation in Aplysia. This possibility takes on added significance in view of the recent findings of Krasne and colleagues (Krasne, 1993; Krasne and Teshiba, 1995), described above, who have provided evidence for descending inhibition as a mechanism for habituation of the tail-flip response in crayfish.

\section{Functional implications of distributed facilitation and decrement within reflex circuits}

Our results suggest that during habituation, a facilitating process is activated early in the system at the sensory neurons, and a decrementing process is activated further downstream at interneuronal loci. What functional advantage might be gained by this differential distribution of facilitation and decrement within a reflex circuit? One possibility is that initial facilitation may provide an increase in signal gain before other modulatory processes are brought into play at subsequent sites in the reflex circuit. Later decrement, downstream from the sensory neuron level, might enable more neuronal processing to occur before the signal is ultimately reduced as a result of synaptic depression and/or inhibition. In this way, more information from other parts of the organism might be integrated before the system "decides" to cease responding to a repeated stimulus that proves to be nonthreatening.

The emphasis on interneurons as potential loci for habituation brings our results examining habituation of tail-elicited reflexes in Aplysia into register with several other model systems used to study habituation, such as crayfish escape (Krasne and Teshiba, 1995), frog spinal cord (Farel, 1974), rat audition (Davis et al., 1982), spinal cat (Spencer et al., 1966; Wickelgren, 1967; Thompson and Glanzman, 1976), and human eyeblink (Sanes and Ison, 1983). In all of these systems it seems that habituation is mediated at interneuronal sites, perhaps suggesting a general design feature in these diverse systems for the expression of this fundamental form of learning.

\section{REFERENCES}

Buonomano DV, Cleary LJ, Byrne JH (1992) Inhibitory neuron produces heterosynaptic inhibition of sensory-to-motor neuron synapse in Aplysia. Brain Res 577:147-150.

Byrne JH (1982) Analysis of synaptic depression contributing to habituation of gill-withdrawal reflex in Aplysia californica. J Neurophysiol 48:431-438.

Byrne JH (1987) Cellular analysis of associative learning. Physiol Rev 67:329-439.

Carew TJ, Sahley CL (1986) Invertebrate learning and memory: from behavior to molecules. Annu Rev Neurosci 9:435-487.

Carew TJ, Castellucci VF, Kandel ER (1971) Analysis of dishabituation and sensitization of the gill withdrawal reflex in Aplysia. Int $\mathbf{J}$ Neurosci 2:79-98

Carew TJ, Pinsker HM, Kandel ER (1972) Long-term habituation of a defensive withdrawal reflex in Aplysia. Science 175:451-454.

Castellucci VF, Pinsker H, Kupfermann I, Kandel ER (1970) Neuronal mechanisms of habituation and dishabituation of the gill-withdrawal reflex in Aplysia. Science 167:1745-1748.

Castellucci VF, Carew TJ, Kandel ER (1978) Cellular analysis of longterm habituation in the gill withdrawal reflex of Aplysia californica. Science 202:1306-1308.

Clark GA, Kandel ER (1984) Branch-specific heterosynaptic facilitation in Aplysia siphon sensory cells. Proc Natl Acad Sci USA 81:2577-2581.

Clatworthy AL, Walters ET (1993) Activity-dependent depression of mechanosensory discharge in Aplysia. J Neurophysiol 70:1195-1209.

Cleary LJ, Byrne JH (1993) Identification and characterization of a multifunctional neuron contributing to defensive arousal in Aplysia. J Neurophysiol 70:1767-1776.

Cleary LJ, Byrne JH, Frost WN (1995) Role of interneurons in defensive withdrawal reflexes in Aplysia. Learn Memory 2:133-151.

Davis M, Parisi T, Gendelman DS, Tischler M, Kehne JH (1982) Habituation and sensitization of startle reflexes elicited electrically from the brainstem. Science 218:688-690.

Farel PB (1974) Dual processes control response habituation across a single synapse. Brain Res 72:323-327.

Fischer TM, Carew TJ (1993) Activity-dependent potentiation of recurrent inhibition: a mechanism for dynamic gain control in the siphon withdrawal reflex of Aplysia. J Neurosci 13:1302-1314.

Frost WN, Kandel ER (1995) Structure of the network mediating siphonelicited siphon withdrawal in Aplysia. J Neurophysiol 73:2413-2427.

Frost WN, Clark GA, Kandel ER (1988) Parallel processing of shortterm memory for sensitization in Aplysia. J Neurobiol 19:297-334.

Goldsmith JR, Byrne JH (1993) Bag cell extract inhibits tail-siphon withdrawal reflex, suppresses long-term but not short-term sensitization and attenuates sensory-to-motor neuron synapses in Aplysia. J Neurosci 13:1688-1700.

Hawkins RD, Frost L (1995) Contribution of LE siphon sensory neurons to habituation, dishabituation, and sensitization of the gill withdrawal reflex of Aplysia. Soc Neurosci Abstr 21:1024.

Hawkins RD, Frost L (1996) Contribution of monosynaptic EPSPs from LE siphon sensory neurons to mediation and habituation of the gill and siphon withdrawal reflex in Aplysia. Soc Neurosci Abstr, in press.

Hawkins RD, Castellucci V, Kandel ER (1981) Interneurons involved in mediation and modulation of gill withdrawal reflex in Aplysia. I. Identification and characterization. J Neurophysiol 45:304-314.

Hawkins RD, Clark CA, Kandel ER (1987) Cell biological studies of learning in simple vertebrate and invertebrate systems. In: Handbook of physiology, Sec I, The nervous system, Vol V, Higher functions of the nervous system (Mountcastle VB, Plum F, Geiger SR, eds), pp 25-83. Bethesda, MD: American Physiological Society.

Hawkins RD, Kandel ER, Siegelbaum SA (1993) Learning to modulate transmitter release: themes and variations in synaptic plasticity. Annu Rev Neurosci 16:625-665.

Hickie C, Walters ET (1995) Motor neuronal control of tail-directed and head-directed siphon responses in Aplysia californica. J Neurophysiol 74:307-321. 
Kaplan SW, Kandel ER, Hawkins RD (1993) Plasticity in the monosynaptic component of the Aplysia gill withdrawal reflex during habituation, dishabituation, and sensitization. Soc Neurosci Abstr 19:16.

Klein M, Shapiro E, Kandel ER (1980) Synaptic plasticity and the modulation of the $\mathrm{Ca}^{2+}$ current. J Exp Biol 89:117-157.

Krasne FB (1969) Excitation and habituation of the crayfish escape reflex: the depolarizing response in lateral giant fibres of the isolated abdomen. J Exp Biol 50:29-46.

Krasne FB (1993) Tonic descending inhibition contributes to habituation of crayfish lateral giant escape reaction. Soc Neurosci Abstr 19:816.

Krasne FB, Teshiba TM (1995) Habituation of an invertebrate escape reflex due to modulation by higher centers rather than local events. Proc Natl Acad Sci USA 92:3362-3366.

Kupfermann I, Castellucci V, Pinsker H, Kandel ER (1970) Neuronal correlates of habituation and dishabituation of the gill-withdrawal reflex in Aplysia. Science 167:1743-1745.

Montarolo PG, Kandel ER, Schacher ER (1988) Long-term heterosynaptic inhibition in Aplysia. Nature 333:171-174.

Pinsker H, Kupfermann I, Castellucci V, Kandel ER (1970) Habituation and dishabituation of the gill-withdrawal reflex in Aplysia. Science 167:1740-1742.

Sanes JN, Ison JR (1983) Habituation and sensitization of components of the human eyeblink reflex. Behav Neurosci 97:833-836.

Schacher S, Montarolo PG (1991) Target-dependent structural changes in sensory neurons of Aplysia accompany long-term heterosynaptic inhibition. Neuron 6:679-690.

Scholz KP, Byrne JH (1987) Long-term sensitization in Aplysia: biophysical correlates in tail sensory neurons. Science 235:685-687.

Spencer WA, Thompson RF, Neilson DR (1966) Decrement of ventral root electrotonus and intracellularly recorded PSPs produced by iterated cutaneous afferent volleys. J Neurophysiol 29:253-274.

Stopfer M, Carew TJ (1987) Quantitative analysis of the relation between gill amplitude and siphon duration in the defensive withdrawal reflex of Aplysia. Behav Neurosci 101:292-295.

Stopfer M, Carew TJ (1994) Homosynaptic depression in tail sensory neurons is not the mechanism of habituation of tail-induced tail or siphon withdrawal in Aplysia. Soc Neurosci Abstr 20:1073.
Stopfer M, Chen X, Tai Y, Huang GS, Carew TJ (1996) Site-specificity of short-term and long-term habituation in the tail-elicited siphon withdrawal reflex of Aplysia. J Neurosci 16:4923-4932.

Thompson RF, Glanzman DL (1976) Neural and behavioral mechanisms of habituation and sensitization. In: Habituation: perspectives on child development, animal behavior and neurophysiology (Tighe TJ, Leaton RN, eds), pp 49-93. New York: Wiley.

Thompson RF, Spencer WA (1966) Habituation: a model phenomenon for the study of the neural substrates of behavior. Psychol Rev 73:16-43.

Trudeau L-E, Castellucci VF (1993) Sensitization of the gill and siphon withdrawal reflex of Aplysia: multiple sites of change in the neuronal network. J Neurophysiol 70:1210-1220.

Walters ET (1987a) Site-specific sensitization of defensive reflexes in Aplysia: a simple model of long-term hyperalgesia. J Neurosci 7:400-407.

Walters ET (1987b) Multiple sensory neuronal correlates of site-specific sensitization in Aplysia. J Neurosci 7:408-417.

Walters ET, Byrne JH, Carew TJ, Kandel ER (1983) Mechanoafferent neurons innervating the tail of Aplysia: response properties and synaptic connections. J Neurophysiol 50:1522-1542.

White JA, Cleary LJ, Ziv I, Baxter DA, Byrne JH (1993) The role of interneurons in controlling the tail-withdrawal reflex in Aplysia: a network model. J Neurophysiol 70:1777-1786.

Wickelgren BG (1967) Habituation of spinal interneurons. J Neurophysiol 30:1425-1438.

Wine JJ, Krasne FB, Chen L (1975) Habituation and inhibition of the crayfish lateral giant fibre escape response. J Exp Biol 62:771-782.

Wright WG, Marcus EA, Carew TJ (1991) A cellular analysis of inhibition in the siphon withdrawal reflex of Aplysia. J Neurosci 11:2498-2509.

Zucker RS (1972) Crayfish escape behavior and cervical synapses. II. Physiological mechanisms underlying behavioral habituation. J Neurophysiol 35:621-637.

Zucker RS, Kennedy D, Selverston AI (1971) Neuronal circuit mediating escape responses in crayfish. Science 173:645-650. 